Elise Julien

\title{
Paris und Berlin nach dem Ersten Weltkrieg: Eine symbolische Nationalisierung der Hauptstädte?
}

Auch die Geschichtsschreibung des Ersten Weltkrieges war von den großen Änderungen betroffen, welche die Wissenschaftsdisziplin im Laufe der letzten Jahrzehnte geprägt haben. Ihr Schwerpunkt hat sich vom Bereich Wirtschaft zum Bereich Gesellschaft und dann vom Bereich Gesellschaft hin zum Bereich Kultur verschoben ${ }^{1}$. Antoine Prost und Jay Winter haben gezeigt, wie drei große historiografische Konfigurationen aufeinander folgten: von einer Geschichte des militärischen und diplomatischen Krieges zu einer Gesellschafts- und Wirtschaftsgeschichte und schließlich zu einer als Kultur- und Gesellschaftsgeschichte bezeichneten Darstellung, in der die Kultur zum strukturierenden Paradigma erhoben wird, auch wenn andere Ansätze nicht ausgeschlossen sind ${ }^{2}$.

Dabei haben sich die Historiker bemüht, den Krieg nicht mehr ausschließlich streng chronologisch zu betrachten und sich intensiver mit den Übergangsphasen zu Beginn und am Ende des Konflikts zu befassen. So sind zahlreiche Studien über die Art der Beendigung des Krieges erschienen ${ }^{3}$. Über die alleinige Betrachtung der Übergangsphasen hinaus hat die Erforschung der Erinnerung und des Gedenkens zudem einer längerfristigen Perspektive den Vorzug gegeben, wobei der Krieg zwar immer noch der zentrale Bezugspunkt ist, es aber nicht so sehr darum geht herauszufinden, was geschehen ist, sondern vielmehr darum, wie die Zeitgenossen mit dieser Vergangenheit umgegangen sind und wie sie sie dargestellt haben ${ }^{4}$. Damit befindet man sich im Zentrum der Kultur, deren zeitliche Dimension in ge-

1 Michel Vovelle, De la cave au grenier. Un itinéraire en Provence au XVIII siècle, Québec 1980. Übersetzung des vorliegenden Aufsatzes durch Bundesprachenamt und Jörg Echternkamp.

2 Antoine Prost et Jay Winter, Penser la Grande Guerre. Un essai d'historiographie, Paris 2004.

3 Démobilisations culturelles après la Grande Guerre. Ed. par John Horne. In: Revue 14-18 Aujourd'hui - Today - Heute, 5 (2002); Bruno Cabanes, La victoire endeuillée. La sortie de guerre des soldats français 1918-1920, Paris 2004; Sortir de la Grande Guerre. Le monde et l'après 1918. Ed. par Stéphane Audoin-Rouzeau et Christophe Prochasson, Paris 2008. In Deutschland konzentriert sich die Forschung über die Wege der physischen und mentalen Fortsetzung des Krieges in die Friedenszeit auch durch Kriegsmythen: Kriegsende 1918. Ereignis, Wirkung, Nachwirkung. Im Auftrag des MGFA hrsg. von Jörg Duppler und Gerhard P. Groß, München 1999; Hans Mommsen, Der Erste Weltkrieg und die Nachkriegsordnung. Sozialer Wandel und Formänderung der Politik, Köln 2000; Der verlorene Frieden. Politik und Kriegskultur nach 1918. Hrsg. von Jost Düllfer und Gerd Krumeich, Essen 2002; Kriegsenden, Nachkriegsordnungen, Folgekonflikte. Wege aus dem Krieg im 19. und 20. Jahrhundert. Im Auftrag des MGFA hrsg. von Jörg Echternkamp, Freiburg i.Br. 2012; Jeffrey Verhey, Der »Geist von 1914« und die Erfindung der Volksgemeinschaft, Cambridge 2000; Boris Barth, Dolchstoßlegenden und politische Desintegration. Das Trauma der deutschen Niederlage im Ersten Weltkrieg 1914-1933, Düsseldorf 2003.

4 Pierre Nora, Mémoire collective. In: La nouvelle histoire. Ed. par Jacques Le Goff et Jacques Revel, Paris 1978, S. 400. Siehe auch: Les lieux de mémoire. Ed. par Pierre Nora, Paris 1984-1997. 
wisser Weise die Erinnerung ist. Hier zählt die Herangehensweise jedoch ebenso viel wie der Betrachtungsgegenstand: Die Erinnerungsgeschichte des Krieges, die mit den Vorstellungen wie mit der sozialen Praxis verbunden ist, ist gleichzeitig eine »untrennbare Gesellschafts- und Kulturgeschichte ${ }^{5}$. Eine solche Kulturgeschichte ist das Erbe einer deutschen Ideengeschichte und einer französischen Geschichte der Repräsentationen, die nicht mehr in Konkurrenz zur Gesellschaftsgeschichte stehen. Sie ist verbunden mit drei Bereichen der sozialen Ordnung: den kollektiven Darstellungen, welche die Identitäten formen; die Praktiken, mit denen diese Identitäten betont werden können; und den institutionalisierten und objektivierten Ausdrucksformen, durch welche die Gruppen ihre Existenz unterstreichen ${ }^{6}$.

Unter den Forschungsgegenständen, die mit diesem methodischen Ansatz untersucht werden, hat der Totenkult, der nach dem Krieg eingeführt wurde, zu zahlreichen Studien geführt. Diese befassen sich mit der Wirkung der Trauer und dem Umgang mit dieser Trauer durch den Einzelnen, mit der Entwicklung kollektiver Mythen und der Einführung politischer Riten ${ }^{7}$. Zudem haben besondere Erinnerungsorte, die Kriegerdenkmäler, die Aufmerksamkeit der Historiker auf sich gezogen. Insgesamt jedoch werden in den Studien die Hauptstädte größtenteils nicht behandelt und es wird kein Vergleich gewagt, insbesondere nicht zwischen Frankreich und Deutschland und noch weniger zwischen den beiden Hauptstädten ${ }^{8}$.

Der folgende Vergleich von Paris und Berlin soll klären, welche historische Entwicklungen speziell auf die jeweiligen Länder und welche möglicherweise auf die jeweiligen Besonderheiten der beiden Städte zurückzuführen sind. Er soll darüberhinaus Gewissheiten und vertraute Sichtweisen infrage stellen und so unseren Verständnishorizont erweitern. Unter diesen Bedingungen bleibt die vergleichende Geschichte das einzige Mittel zur Beantwortung von Fragen, die sich die nicht vergleichenden Arbeiten in der Regel nicht stellen können'. Zum Kontext des Geden-

5 Antoine Prost, Sociale et culturelle, indissociablement. In: Pour une histoire culturelle. Ed. par Jean-Pierre Rioux et Jean-François Sirinelli, Paris 1997, S. 131-146.

$6 \quad$ Ute Daniel, Kompendium Kulturgeschichte. Theorien, Praxis, Schlüsselwörter, Frankfurt a.M. 2006; Roger Chartier, Au bord de la falaise. L'histoire entre certitudes et inquiétude, Paris 1998; Pascal Ory, L'histoire culturelle, Paris 2004.

7 George Mosse, Fallen Soldiers. Reshaping the Memory of the World Wars, Oxford 1991; Daniel Sherman, The Construction of Memory in the Interwar France (1914-1940), Chicago, IL 1999; Jay Winter, Sites of Memory, Sites of Mourning. The Great War in European Cultural History, Cambridge 1995; Jay Winter, Remembering War. The Great War between Memory and History in the Twentieth Century, New Haven, CT 2006; Oliver Janz, Das Symbolische Kapital der Trauer. Nation, Religion und Familie im italienischen Gefallenenkult des Ersten Weltkriegs, Berlin 2009; Gefallenengedenken im globalen Vergleich. Nationale Tradition, politische Legitimation und Individualisierung der Erinnerung. Hrsg. von Manfred Hettling und Jörg Echternkamp, München 2013.

8 Antoine Prost, Les anciens combattants, Paris 1977; Annette Becker, Les monuments aux morts, mémoire de la Grande Guerre, Paris 1988; Monuments de mémoire. Les monuments aux morts de la Première Guerre mondiale. Ed. par Philippe Rivé, Paris 1991; Reinhart Koselleck, Zur politischen Ikonologie des gewaltsamen Todes. Ein deutsch-französischer Vergleich, Basel 1998; Meinhold Lurz, Kriegerdenkmäler in Deutschland, Heidelberg 1985-1987; Martina Weinland, Kriegerdenkmäler in Berlin, 1870 bis 1930, Frankfurt a.M. 1990; Christian Saehrendt, Der Stellungskrieg der Denkmäler. Kriegerdenkmäler im Berlin der Zwischenkriegszeit (1919-1939), Berlin 2004.

9 Thomas Welskopp, Stolpersteine auf dem Königsweg. Methodenkritische Anmerkungen zum internationalen Vergleich in der Gesellschaftsgeschichte. In: Archiv für Sozialgeschichte, 35 (1995), S. 367. Siehe auch Hartmunt Kaelble, Der historische Vergleich. Eine Einführung zum 19. und 20. Jahrhundert, Frankfurt a.M. 1999. 
kens gehören die politischen Traditionen und gesellschaftlichen Strukturen, weil sie grundlegend unterschiedliche Entwicklung des Kriegsgedenkens erklären.

Nach dem Ersten Weltkrieg befanden sich Frankreich und Deutschland in einer entgegengesetzten Situation, insbesondere was den seit 1914 sehnlichst erwarteten Sieg betraf. Im siegreichen Frankreich mischten sich die Heldengeschichten über den Konflikt mit pazifistischen Neuinterpretationen, was allmählich zu einer gewissen Ablehnung des Krieges im kollektiven Gedächtnis führte. In Deutschland, das statt eines erhofften Sieges eine schwere Niederlage hinnehmen musste, führte die Mystifizierung der Kriegserlebnisse zu einer Fortsetzung des Konflikts. Sie widersprach den Versuchen, ein realistisches Bild vom Krieg zu präsentieren, um seine Schrecken anzuprangern; die Erinnerung blieb zwiespältig und verhinderte so eine kulturelle Lösung des Konflikts ${ }^{10}$.

Das Außergewöhnliche der Hauptstädte im Hinblick auf die Erinnerungspraktiken ist zum Teil darauf zurückzuführen, dass sich in ihnen die Charakteristika und Symbole der Nation konzentrieren. Paris und Berlin fügten sich im Jahr 1918 somit voll und ganz in ihren jeweiligen nationalen Rahmen ein. Trotzdem sind die Hauptstädte etwas anderes als ein einfacher Spiegel dessen, was im jeweiligen Land passiert: Als lokale Prismen der nationalen Geschichte weisen sie überdies von Land zu Land strukturelle Ähnlichkeiten auf, die einen Vergleich und eine Gegenüberstellung jenseits aller Grenzen erleichtern.

In Paris und in Berlin wirkten unterschiedliche Akteure auf das Gedenken an den Krieg ein, und ein bedeutender Teil dieser Beiträge ist nationalen Akteuren zuzuschreiben. Diese können vom Staat abhängig sein, aber nicht nur: Alle in beiden Ländern landesweit organisierten religiösen, politischen oder berufsständischen Gruppierungen der Zivilgesellschaft oder Gruppierungen mit noch anderen Interessenschwerpunkten können nämlich bestrebt sein, sich in der jeweiligen Hauptstadt niederzulassen, um dort vertreten zu sein, Anerkennung und Legitimität zu suchen und durch verschiedene Eroberungsstrategien ihre Geschichte und Geografie zu beeinflussen.

Mehrere Phänomene wirkten zusammen: einerseits die »Nationalisierung « des Gedenkens durch entsprechende Darstellungen in den Hauptstädten, andererseits die »Nationalisiserung « der Hauptstädte selbst durch die dortige Anhäufung von Zeichen des Gedenkens. Um diesen Prozess zu beleuchten, lohnt es sich, vor allem die nationalen Kriegerdenkmäler eingehender zu untersuchen, über deren Gestaltung die Zeitgenossen debattierten und die dann mit unterschiedlichem Abstand zum Kriegsende errichtet wurden.

\section{Eroberung der Hauptstädte}

Wegen des politischen, gesellschaftlichen und kulturellen Gewichts der Hauptstädte wird allem, was sich dort abspielt, tendenziell ein zu hoher Stellenwert gegeben. Dieses Phänomen wird durch die monumentale Symbolik dieser Städte unterstützt, die jene Symbole zusammenfasst, die in einzelnen Städten im Lande

10 Elise Julien, Paris, Berlin, la mémoire de la guerre 1914-1933, Rennes 2010. Dieser Aufsatz ist die überarbeitete Fassung eines Großteils von Kapitel 5. 
verteilt sind: In Deutschland wie in Frankreich verläuft der Triumphweg par excellence »Unter den Linden«bzw. auf den »Champs-Élysées«, und auch das Gedenken an die Toten der Arbeiterbewegung als Opfer der Märzrevolution von 1848 findet auf dem Friedhof der Märzgefallenen in Berlin bzw. für die im Zuge des Aufstandes der Pariser Kommune 1871 Füsilierten an der »Mur des fédérés « in Paris statt. Angesichts dieses massiven Prestiges oder zumindest dieser Anhäufung von Symbolen, von denen jeder [i.e. Mensch] nur einen Teilaspekt repräsentiert, gibt es zahlreiche soziale Gruppen, die sich in den Hauptstädten vertreten sehen wollen. In Anbetracht der Vielzahl der Fälle soll hier der Fall religiöser und politischer Gruppierungen betrachtet werden.

Am Ende des Weltkrieges ließ die katholische Kirche Frankreichs in der Kathedrale Notre-Dame ein »Te deum « feiern. Im darauffolgenden Jahr wurde die Basilika Sacré-Cœur geweiht, deren Errichtung kurz nach einem anderen Krieg, dem Deutsch-Französischen Krieg von 1870 bis 1871, geplant worden war. Und als die kirchlichen Würdenträger an die Schaffung eines wirklich neuen Symbols zur Erinnerung an den Krieg dachten, zogen sie ebenfalls nur Paris als Standort hierfür in Betracht. Sie verwiesen dabei auf das am 13. September 1914 auf dem Kirchenvorplatz von Notre-Dame von Kardinal Amette vorgetragene Gelübde, in dem er versprochen hatte, der französischen Nationalheiligen Jeanne d'Arc im Falle eines Sieges eine Basilika als Votivdenkmal für das Heil und den Triumpf des Landes zu errichten ${ }^{11}$. Das Versprechen des Pariser Kardinals wurde zum Versprechen der Kirche Frankreichs: Nach der Heiligsprechung von Jeanne d'Arc 1920 durch Papst Benedikt XV. wollte die Kirche mehr als je zuvor ein grandioses Zeichen der Würdigung setzen. Dafür »ist eine nationale Kirche erforderlich, deren rechtmäßiger Platz in der Hauptstadt ist «. Den Kirchen, welche die nunmehr Heiliggesprochene bereits ehren, »fehlt nämlich etwas ganz Entscheidendes: der nationale Charakter $\ll^{12}$.

Die Wahl des Ortes fiel auf Saint-Denys de la Chapelle im 18. Arrondissement, wo Jeanne d'Arc im September 1429 auf dem Weg nach Paris Station gemacht haben soll. Mit dem künftigen Denkmal in Paris verbanden sich ehrgeizige Hoffnungen, die durch die Nähe anderer Symbole noch verstärkt wurden: Nicht weit von dem 1920 unter dem Arc de Triomphe angelegten Grab des Unbekannten Soldaten entfernt sollte die Kirche Saint-Denys der Gedenkort für den »bekanntesten Soldaten ${ }^{13}{ }^{13}$ der französischen Geschichte sein. Im Juni 1926 wurde ein Wettbewerb für den Bau einer Basilika ausgeschrieben und den ersten Preis erhielt der Entwurf von Georges Closson. Die Realisierung dieses Entwurfs war jedoch immer noch abhängig von der Genehmigung des Stadtrats und der erforderlichen Finanzierung. Schließlich entstand eine Kirche in einer viel einfacheren Ausführung als ursprünglich geplant. Da an diesem Ort kein großes Bauwerk errichtet wurde, er-

11 La Semaine religieuse de Paris, 19.9.1914. Archives historiques de l'Archevêché de Paris (AHAP).

12 Rapport présenté à l'Assemblée de MM. Les curés de Paris sur le projet d'édification de la basilique Sainte Jeanne d'Arc, 9.12.1925. AHAP, fonds des paroisses, carton »Saint-Denys de la Chapelle/Construction de la basilique Sainte Jeanne d'Arc«.

13 Broschüre »Payons nos dettes. Une basilique nationale à Sainte Jeanne d’Arc«, 1924, S. 10. AHAP, fonds des paroisses, carton »Saint-Denys de la Chapelle/Construction de la basilique Sainte Jeanne d'Arc«. 
folgte die Umgestaltung der Krypta der Basilika Sacré-Cœur in eine Gedenkstätte für die Gefallenen katholischen Glaubens ${ }^{14}$.

Diese Suche nach einem geweihten Ort in Paris war keine Eigenart des Katholizismus. Bei den Juden übernahm der Dachverband der jüdischen Gemeinden, das Konsistorium in Paris, die Aufgabe, die Namen der Toten der einzelnen Gemeinden zu erfassen und in ein nationales goldenes Buch einzutragen ${ }^{15}$. Im Jahr 1923 enthüllte dieses Konsistorium in der Großen Synagoge in der Rue de la Victoire eine Gedenktafel mit den Namen der Toten der Pariser Gemeinde und weihte ein Denkmal mit einer viel umfassenderen Intention ein: Helm, Gewehr, Fahne und Gesetzestafeln würdigen alle für Frankreich gefallenden Juden ${ }^{16}$. Erst viel später, im Jahr 1938, nach der Einweihung des Beinhauses in Douaumont und vor dem Hintergrund eines zunehmenden Antisemitismus wurde in der Nähe von Verdun ein Denkmal eingeweiht, das allen von 1914 bis 1918 für Frankreich gefallenen französischen Juden gewidmet war. Für die Muslime wurde die zwischen 1922 und 1926 erbaute Große Pariser Moschee zu Ehren der 100000 muslimischen Kriegsteilnehmer vom französischen Staat eingeweiht; dort findet sich eine Stele zur Erinnerung an die im Krieg gefallenen Muslime. Auch diese Stele gab es lange vor der Stele, die den für Frankreich gefallenen muslimischen Soldaten gewidmet ist und 1959 in Verdun vor dem Hintergrund der Entkolonisierung aufgestellt wurde ${ }^{17}$.

In Deutschland dagegen gab es derartige Architekturprojekte nicht. Die Niederlage und die Gesamtsituation des Landes erklären wahrscheinlich die geringere Neigung zu grandiosen Plänen. Dabei hätten nach Niederlage und Revolution auch Denkmäler gebaut werden können, die als Zeichen der Sühne gedient hätten. In der Hauptstadt und ihrer unmittelbaren Umgebung vereinten die Garnisonkirchen die Merkmale eines zugleich militärischen und religiösen Gedenkens. Obwohl die Berliner Garnison nach dem Krieg aufgelöst worden war, blieben die Garnisonkirchen bestehen, insbesondere in Berlin-Neukölln und Potsdam. Als Symbole für die gesamte preußische Armee waren sie jedoch vor allem Zufluchtsstätten für lokale patriotische und Regimentsvereinigungen, für die sie als Hüter der Traditionen fungierten. Dennoch wurden hier wie schon nach vorherigen Konflikten die Fahnen der am Krieg beteiligten preußischen Regimenter aufbewahrt Fahnen, die ebenso militärische Symbole wie geheiligte Reliquien des Schlachtfeldes waren. Die Anziehungskraft der deutschen Hauptstadt für religiöse Würdenträger kann als gering angesehen werden. Denn die Garnisonkirchen gaben sich damit zufrieden, ihre Traditionen fortzuführen, und diese wurden, wenn es sich um preuBische Traditionen handelte, hauptsächlich in Berlin ausgeübt.

Symbole, die sich in den Hauptstädten und in Potsdam befanden, konnten aber auch eine unmittelbare politische Aussage haben und so das Misstrauen der Regierungen erwecken. Mit dem allmählichen Einsetzen der Dritten Republik versuchte die französische Regierung, die Straße zum Raum für Feste und Gedenkfeiern $\mathrm{zu}$ machen, um ihr damit die negative Konnotation und subversive

14 Annette Becker, La guerre et la foi. De la mort à la mémoire, 1914-1930, Paris 1994, S. $132 \mathrm{f}$.

15 Les Israélites dans l'armée française, Angers 1921.

16 Philippe Landau, Les juifs de France et la Grande Guerre. Un patriotisme républicain, Paris 1999, S. 179 f.

17 Ein Denkmal, das das Secrétariat d'Etat aux Anciens combattants finanziert hatte, wurde dort im Übrigen am 25.6.2006 eingeweiht. 
Bedeutung zu nehmen. Demonstrationen waren nicht Teil der garantierten demokratischen Freiheiten, und ihre eventuelle Tolerierung hing vom jeweiligen Bürgermeister oder Präfekten ab. Bis Anfang der dreißiger Jahre des 20. Jahrhunderts war die Toleranz in Paris jedoch viel schwächer ausgeprägt als anderswo ${ }^{18}$. Diese strengen Bestimmungen wurden umso strikter angewendet, als sich die politischen Mehrheitsverhältnisse in der Stadt, die sich um die Jahrhundertwende zugunsten der Rechten geändert hatten, als dauerhaft erwiesen. In Deutschland dagegen, nach der Gründung der Weimarer Republik, versuchte die neue Regierung nach den Kämpfen der Revolution ein neues Kapitel aufzuschlagen: Berlin sollte wieder ein Raum von Recht und Ordnung werden. Die Weimarer Verfassung garantierte den Deutschen in Artikel 123 »das Recht, sich ohne Anmeldung oder besondere Erlaubnis friedlich und unbewaffnet zu versammeln«. Das Gesetz legte aber auch Folgendes fest: »Versammlungen unter freiem Himmel können durch Reichsgesetz anmeldepflichtig gemacht und bei unmittelbarer Gefahr für die öffentliche Sicherheit verboten werden «. Hinzu kamen Sondergesetze, die Demonstrationen radikal einschränkten; so erlaubte das Republikschutzgesetz vom 21. Juli 1922 das Verbot von Versammlungen und Gruppierungen, die sich gegen die Republik richteten. Die Einschätzung der Lage wurde den Ländern überlassen. In den 1920er Jahren wurde vom Demonstrationsverbot umfassend Gebrauch gemacht, vor allem in Berlin.

Trotz dieser Gesetze und restriktiver Durchführungsmaßnahmen fanden in Paris und in Berlin in den Nachkriegsjahren zahlreiche Demonstrationen statt. Die Erinnerung an den Krieg bot außerdem die Möglichkeit, das Gebiet der Hauptstädte aus Anlass des Gedenkens geradezu zu besetzen: Die Demonstranten konnten sich auf das Gedenken an die Gefallenen berufen - ein Argument, das in Gesellschaften, in denen dieses Gedenken eine nationale Pflicht war, nur schwer entkräftet werden konnte. So waren vom Demonstrationsverbot auf dem Gebiet von Paris, das die Regel blieb, Märsche ausgenommen, an denen überwiegend Kriegsveteranen teilnahmen und die mit traditionellen Umzügen gleichgesetzt wurden. Diese Praxis führte insgesamt dazu, dass den Äußerungen rechter Gruppierungen eher Vorschub geleistet wurde. Manche Umzüge waren direkt von politischen Überlegungen bestimmt. Am 11. Juli 1926 und am 6. Februar 1934 hielten Kriegsveteranen ihre Parade in Paris ab, weil sie hofften, die Mehrheitsverhältnisse im Parlament zu kippen.

Die Linke benutzte das Gedenken ebenfalls als Vorwand für Demonstrationen in Paris. So marschierten 300000 Demonstranten am 6. April 1919 zum Gedenken an den am 31. Juli 1914 ermordeten Reformsozialisten Jean Jaurès, nachdem sein Mörder freigesprochen worden war. Am 23. November 1924 war die Linke nach der Rückkehr des Linkskartells (»Cartel des gauches«) an die Macht erneut in Massen auf der Straße, um die Überführung der sterblichen Überreste von Jaurès ins Panthéon zu begleiten. Danielle Tartakowsky sieht darin für Paris den Beginn einer zaghaften Rückeroberung der Straße durch die Arbeiterbewegung. Angesichts des Eindrucks, dass Paris selbst der Rechten gehörte, dienten die Vorstädte als Zufluchtsort und zugleich als Ausgangspunkt für Märsche auf Paris. Das nährte die

18 Danielle Tartakowsky, La construction sociale de l'espace politique. Les usages de la place de la Concorde des années 1880 à nos jours. In: French Historical Studies, 27 (2004), 1, S. 145-173. 
Vorstellung von der Einkreisung der Stadt durch rote Vororte ${ }^{19}$. Mit der Rückkehr der Rechten in die Regierung im Juli 1926 sollte die Straße ein Ort der Ordnung bleiben. Erst nach Februar 1934 wuchs die Toleranz gegenüber Demonstrationen, insbesondere antifaschistischen. Am 11. November 1935 konnten die pazifistischen Veteranen die französische Hauptstadt dann »einnehmen«, als sie auf den ChampsÉlysées eine Parade abhielten ${ }^{20}$. Damit zeigten sie, dass der Unbekannte Soldat ein einigendes Symbol auch für die extreme Linke war, genauso wie sie daran erinnerten, dass die seit den 1920er Jahren damit verbundenen militärischen und patriotischen Rituale nicht unverrückbar waren. Die roten Fahnen unter dem Arc de Triomphe sollten weniger das Denkmal in Frage stellen als signalisieren, dass dieses auch von jenen Gruppierungen in Besitz genommen worden war, die hier üblicherweise nicht vertreten waren.

Berlin seinerseits war eine Garnisonstadt, in der das Gedenken an die Kriegsgefallenen oftmals die Form von Regimentstreffen oder militärischen Feierlichkeiten annahm. Berlin war aber auch eine linke Stadt, und die in der Provinz verankerten nationalistischen und monarchistischen Vereinigungen verspürten den Drang, sie symbolisch zu erobern. So veranstaltete der paramilitärische Wehrverband »Stahlhelm, Bund der Frontsoldaten « Sternfahrten aus ganz Deutschland nach Berlin und organisierte Propagandamärsche auf den Straßen der Hauptstadt. Anlässlich seines Jahrestreffens 1927 erklärte der Verband: »130 000 Männer in friedlicher Absicht, aber in stahlharter Entschlossenheit besetzen die Stadt, um dem roten Berlin das unauslöschliche Merkmal einer gewaltigen vaterländischen Demonstration einzubrennen ${ }^{21}$. 1928 rief der »Stahlhelm « zu einem »Marsch der Hunderttausend zur Eroberung Berlins« auf. Tatsächlich nahmen unter der Aufsicht von 3500 Polizisten einige tausend Personen an einem Marsch durch die Arbeiterbezirke Prenzlauer Berg und Friedrichshain zum Lustgarten teil ${ }^{22}$.

Diese Art von Veranstaltungen stieß regelmäßig auf Anfeindungen, aber die linken Vereinigungen, die sich auf die Veteranen beriefen, konnten sich nicht auf ein gemeinsames Handeln einigen: Die Kommunisten waren, die Internationale auf den Lippen, konsequenterweise vor Ort, was in den Augen der Sozialdemokraten bedeutete, dass rechtskonservativen Gruppen eine Antwort gegeben und damit eine Aufmerksamkeit zuteil wurde, die sie nicht verdienten. Das Totengedenken und die Erinnerung an den Krieg schienen nur noch im Hintergrund von offen politisch motivierten Demonstrationen zu stehen. Derartige Strategien kündigten bereits damals den »Kampf um Berlin $\ll^{23}$ an, der für die NSDAP nach dem von Josef Goebbels formulierten Prinzip Gestalt annahm, dass der Schlüssel zur Macht über Deutschland in Preußen liege. »Wer Preußen hat, der hat das Reich. Und der Weg zur Macht in Preußen geht über die Eroberung von Berlin ${ }^{24}$ «

19 Danielle Tartakowsky, La province sans Paris ou la province contre Paris. In: La manifestation. Ed. par Pierre Favre, Paris 1990, S. 156-177.

20 Danielle Tartakowsky, Stratégies de la rue, 1934-1936. In: Le Mouvement social, 135 (1986), S. 31-62.

21 Bundesblatt des Deutschen Offizierbundes, 15.5.1927, S. 582. Zit. nach Christian Saehrendt, Der Stellungskrieg der Denkmäler. Kriegerdenkmäler im Berlin der Zwischenkriegszeit, 1919-1939, Bonn 2004, S. 50.

22 Vossische Zeitung, 5.2.1928. Zit. nach Saehrendt, Der Stellungskrieg (wie Anm. 8), S. 50.

23 Joseph Goebbels, Kampf um Berlin, München 1932.

24 Der Angriff, 5.10.1930. Zit. nach Andreas Wirsching, Vom Weltkrieg zum Bürgerkrieg? Politischer Extremismus in Deutschland und Frankreich 1918-1933/39. Berlin und Paris im Vergleich, München 1999, S. 465. 
In Frankreich wie in Deutschland herrschte deshalb der Gedanke vor, dass man in der Hauptstadt präsent sein müsse, um sich Gehör zu verschaffen und nationale Aufmerksamkeit zu gewinnen. Die symbolische Stärke der Hauptstädte ermöglicht es nämlich jedem, dort eine Botschaft zu vermitteln und in Szene zu setzen, die auf nationaler Ebene von allen wahrgenommen wird. Dagegen haben die Provinzstädte nur für diejenigen eine symbolische Bedeutung, die in persönlicher Beziehung zu ihnen stehen.

Umgekehrt nehmen die Hauptstädte für das Gedenken eine derart wichtige Stellung ein, dass ihre besonderen Attribute letztlich für das ganze Land - manchmal auch darüber hinaus - zu nationalen Attributen werden. Das zeigt der Fall großer Friedhöfe in Paris und Berlin. Die Räume, die traditionell für das Gedenken und die Besinnung vorgesehen sind, bekamen eine neue Bedeutung, als aufgrund des Krieges Orte gefunden werden mussten, die über dem Tod stehen und eine öffentliche Dankbarkeit bekunden konnten. In dieser Rolle machten sie eine Tendenz zur Nationalisierung besonders sichtbar, die bestimmte Orte in den Hauptstädten betraf.

In Paris entstand 1804 der Friedhof Père Lachaise nach der im 18. Jahrhundert begonnenen Auseinandersetzung um die Verlegung der Friedhöfe außerhalb der Städte aus hygienischen Gründen und wegen Überfüllung. Ab 1860 lag er jedoch wieder mitten in den Arbeitervierteln im Pariser Osten. Bereits 1871 hatte die Regierung versucht, sich des Friedhofs symbolisch zu bemächtigen, indem sie dort mehrere Sühnedenkmäler der Pariser Kommune errichten ließ. Der Sieg der Republikaner über den »Ordre moral«, die Koalition der Rechten, erlaubte es jedoch, dass der Friedhof bis zum Beginn des 20. Jahrhunderts seine Vorrechte als »städtisches Panthéon « wiedererlangte. In den Vorkriegsjahren schien die Stadtverwaltung diesen Ort nicht mehr so sehr in Beschlag zu nehmen. Die neue rechte Mehrheit in der Kommunalpolitik und die Ablehnung der übertriebenen Vorliebe für Statuen begünstigten das ${ }^{25}$.

Mit dem Ersten Weltkrieg änderten sich die Bedingungen für das Bestehen des Friedhofs Père Lachaise zwangsläufig. Wenn auch der Stadtrat zunächst weiter zögerte, Parzellen für neue Denkmäler für die Opfer des Konflikts zuzuteilen, schien er nach dem Waffenstillstand doch bereit, dort ein Denkmal für die Toten der Stadt Paris zu errichten. Die Regierung ihrerseits verzichtete nicht darauf, diesen Ort ihren Wünschen entsprechend zu prägen. Auf Anraten des Ministers für Bildung räumte sie dem Père Lachaise im Rahmen der Feierlichkeiten zum 11. November 1920 einen besonderen Platz ein. Am Fuße des von Paul-Albert Bartholomé geschaffenen Denkmals »Für die Toten « legten Schulkinder zwei Kränze nieder: Der eine ehrte die Auslandsfranzosen, die dem Aufruf des Vaterlandes zur Rückkehr gefolgt waren und ihr Leben für dessen Verteidigung gelassen hatten, der andere erinnerte an die während des Krieges in der Fremde gefallenen Franzosen ${ }^{26}$.

Der Friedhof Père Lachaise drängte sich nun auch als möglicher Ort der Trauer um jene Toten auf, die keine Grabstätte hatten. Er wurde jedoch nicht wegen seiner Bedeutung als Soldatenfriedhof dafür ausgewählt. Dort befindet sich nämlich nur eine kleine Anzahl der in Paris erfassten Soldatengräber des Krieges 1914-1918: Am 11. November 1920 wurden dort zwölf Kränze niedergelegt, wohingegen es

Danielle Tartakowsky, Nous irons chanter sur vos tombes. Le Père-Lachaise, $\mathrm{XIX}^{\mathrm{e}}-\mathrm{XX} \mathrm{X}^{\mathrm{e}}$ siècle, Paris 1999.

26 Archives de Paris (AP), 1326 W/59. 
auf allen Pariser Friedhöfen insgesamt 10295 waren $^{27}$. Vielmehr stellten die Veranstalter immer wieder die nationale Bedeutung des Friedhofs heraus. Durch die Nähe zu zahlreichen »nationalen Berühmtheiten « käme ein Denkmal an diesem Ort nichts Geringerem als »einer Verherrlichung der französischen Seele ${ }^{28}$ gleich, so lautete ihr Argument.

Unter der Schirmherrschaft der Regierung, aber mit Zustimmung des Stadtrats, der die Standorte auf dem Friedhofsgelände zuwies, entstanden in den Nachkriegsjahren auf dem Père Lachaise Denkmäler, deren Bedeutung weit über die Grenzen der französischen Hauptstadt hinausging. So wurde am 19. November 1934 das Denkmal für die belgischen Soldaten und kurz danach, am 16. Dezember 1934, das Denkmal für die tschechoslowakischen Soldaten eingeweiht. In seiner Rede anlässlich der Einweihungszeremonie vertraute der Botschafter der Tschechoslowakei Stephen Osusky in Frankreich dieses Denkmal offiziell »der Mutter Frankreich « an; es sei errichtet »in der berühmtesten Nekropole der französischen Hauptstadt « zum Gedenken an die tschechoslowakischen Soldaten, die für das »ihrer Ansicht nach von Frankreich verkörperte Ideal von Gerechtigkeit und Freiheit « gefallen waren ${ }^{29}$.

Somit wurde der Friedhof Père Lachaise mit Paris, mit Frankreich und mit den von Frankreich verkörperten Werten in Verbindung gebracht. Tatsächlich war der Friedhof kein politischer Zankapfel mehr zwischen dem Stadtrat und der Zentralmacht; er wurde vielmehr zu einem Ort der letzten Ruhe für berühmte Politiker und Künstler. Es handelte sich um Pariser und nationale, aber auch um internationale Berühmtheiten. Die Weltläufigkeit der Stadt hatte eine Form der Internationalisierung zur Folge, die vom Père Lachaise ebenso wie von anderen öffentlichen Orten der Hauptstadt beansprucht wurde ${ }^{30}$. Allgemein gesprochen, weist dieses Phänomen auf die nicht nur patriotische und nationale, sondern auch internationale Rolle der französischen Hauptstadt während des Krieges hin.

In Berlin stellte sich die Lage insofern etwas anders dar, als die Friedhöfe dort weitgehend konfessionelle Friedhöfe blieben. Der große städtische Friedhof Friedrichsfelde im Osten der Stadt wurde erst 1881 angelegt, und wie seine städtischen Vorgänger wurde er vor allem für nicht religiöse Armenbegräbnisse genutzt. Grabstätten der ruhmreichen Toten der Stadt finden sich hier nicht ${ }^{31}$.

Berlin war aber auch der Standort einer alten, zahlenmäßig starken Garnison, was das Vorhandensein bedeutender Soldatenfriedhöfe in der Stadt erklärt. Zu

$27 \mathrm{AP}, \mathrm{VK}^{3} / 211$, Cimetière de l'Est: 12 Gräber von französischen Soldaten (als Opfer von Bombenangriffen notiert). Kriegsgräber befinden sich meistens in den Militärabteilungen der Pariser Friedhöfe innerhalb von Paris (Vaugirard) und in den Vororten (Ivry, Bagneux, Saint-Ouen, Pantin, Suresnes et Neuilly-sur-Seine).

28 René Fiquet, Conseil municipal (CM), 14.3.1921. In: Bulletin municipal officiel (BMO) vom 16.3.1921, S. 1367 f.

29 AP, 1326W/11.

30 Paris erhielt zudem das Denkmal für die amerikanischen Freiwilligen [des Ersten Weltkrieges], das auf der dann umbenannten »Place des Etats-Unis« steht, sowie das Denkmal der französisch-belgischen Entente, das Belgien Frankreich angeboten hatte und das sich auf der Place de l'Alma befindet. AP, VK $\mathrm{VK}^{3} / 225$ und $\mathrm{VK}^{3} / 226$.

31 Joachim Hoffmann, Berlin-Friedrichsfelde. Ein deutscher Nationalfriedhof, Berlin 2001. Elise Julien et Elsa Vonau, Le cimetière de Friedrichsfelde. Construction d'un espace socialiste. In: Le Mouvement social, 237 (2011), S. 91-113. Am Stadtrand wurden große Friedhöfe erst Anfang des 20. Jahrhunderts angelegt, was bis in die Nachkriegszeit einen »Friedhofstreit« zwischen den Kirchen und der Berliner Verwaltung anheizte. 
dem vom preußischen König Friedrich II. zur Versorgung seiner Soldaten gegründeten »Invalidenhaus « gehörte nicht zuletzt ein Friedhof: der »Invalidenfriedhof «. Dort wurden die Bewohner des angrenzenden Invalidenhauses sowie die Mitglieder der dazugehörigen Pfarrgemeinden beerdigt. Schon seit Beginn des 19. Jahrhunderts begrub man auf diesem Friedhof aber auch die sterblichen Überreste derjenigen, die der preußische Freistaat besonders ehren wollte: Generäle, einfache Soldaten oder Zivilbedienstete des Königreiches. Ab 1852 ehrte ein Denkmal jene Soldaten, die der Monarchie 1848 die Treue gehalten hatten. Eine 35 Meter hohe, von einem Adler gekrönte Säule mit einer Treppe im Innern erinnert an die Niederschlagung der Berliner Revolutionskämpfe.

Es dauerte noch bis zum Ersten Weltkrieg, bis der Invalidenfriedhof tatsächlich den Status eines Heldenfriedhofs ${ }^{32}$ erhielt. Nach dem Krieg versuchten die Behörden die Niederlage zu bewältigen, indem sie aus der nationalen Vergangenheit eine konsensstiftende Kraft schöpften. Das beschleunigte die bereits seit einem Jahrhundert bestehende Tendenz, aus diesem Berliner Friedhof eine preußische oder gar deutsche Gedenkstätte zu machen. Insbesondere wurden die sterblichen Überreste einiger Offiziere des Krieges von den Schlachtfeldern überführt oder, falls sie nach dem Ende des Konflikts verstorben waren, direkt an Ort und Stelle beigesetzt $\mathrm{t}^{33}$.

Die Überführung des Leichnams von Manfred von Richthofen 1925 bildete den Höhepunkt dieser Entwicklung. Der »Rote Baron« des Luftkriegs war 1918 in Frankreich gefallen und auf einem Friedhof an der Somme beigesetzt worden. Als seine Familie um die Rückführung seines Leichnams nach Schlesien bat, setzte sich Reichswehrminister Otto Geßler für eine Überführung auf den Invalidenfriedhof ein. Am 18. November 1925 gelangten die sterblichen Überreste dann nach Berlin. Die Aura, die diesen Helden umgab, war ein unverhoffter Glücksfall für die politische Führung der Republik, hoffte sie doch, das Gedenken an diesen ruhmreichen Mann für das neue politische System nutzen zu können. Die Stadt Berlin, der Freistaat Preußen und das Reich finanzierten das am 28. Oktober 1926 auf dem Grab Richthofens enthüllte Grabmal zu gleichen Teilen - das hatte es noch nie gegeben $^{34}$.

Diese Bestattung verstärkte die nationale Deutung des Berliner Friedhofs. Der Friedhofsinspektor Karl Treuwerth veröffentlichte im selben Jahr ein Werk mit dem vielsagenden Titel: »Der Invalidenfriedhof in Berlin. Eine Stätte preußisch-deutschen Ruhmes « ${ }^{35}$. Er trat gegenüber dem Reichskunstwart Edwin Redslob zudem als Verfechter des Projekts eines nationalen Kriegsdenkmals an diesem Ort auf ${ }^{36}$. In diesem Zusammenhang betonte er die historische Dimension der Stätte, ihre Verbindung mit dem Krieg durch die Soldatengräber ${ }^{37}$ und die erst kurz zuvor er-

32 Laurenz Demps, Zwischen Mars und Minerva. Wegweiser über den Invalidenfriedhof, Berlin 1998.

33 Auf dem Feld F des Friedhofs befinden sich z.B. die Skulpturen von Karl von Bülow und Hans von Beseler.

34 Schreiben des Reichsministers des Innern an den Reichskanzler, 16.9.1926, Bundesarchiv (BArch), R 43 I/711.

35 Karl Treuwerth, Der Invalidenfriedhof in Berlin. Eine Stätte preußisch-deutschen Ruhmes, Berlin 1925.

36 Schreiben von Treuwerth an den Reichskunstwart, 28.3.1926, BArch, R 32/358.

37 Er zählte dort 199: Treuwerth, Der Invalidenfriedhof (wie Anm. 35), S. 101-105. Weniger die Präsenz von Kriegsgräbern zählt hier als der Bezug auf die preußisch-deutsche Geschichte. Der neue Friedhof der Berliner Garnison umfasst allein 6000 Kriegsgräber, kann 
folgte Bestattung Richthofens. Die Anwesenheit des Reichspräsidenten und des Reichskanzlers bekräftigte die nationale Bedeutung des Ortes.

Zwar kam das Projekt am Ende nicht zustande, es bestätigte jedoch die nationale Bedeutung, die manche Orte über die spezifisch städtische Bedeutung hinaus erhalten. Im vorliegenden Fall handelte es sich um eine Vereinnahmung durch Preußen und nicht so sehr durch Deutschland: Berlin festigte vor allem seine Rolle als preußische Hauptstadt. Paris hingegen wurde diese Vereinnahmung durch den Nationalstaat selbst über die nationalen Grenzen hinweg zugestanden: Auf dem Friedhof Père Lachaise begegnen einem universalistische Symbole, die der französischen Hauptstadt zugeschrieben wurden. In beiden Fällen widersetzten sich die städtischen Behörden diesem Prozess nicht, sondern arbeiteten mit den nationalen Stellen zusammen. Die jeweiligen Interessen schienen hier zusammenzulaufen. Die Nation machte sich bedeutungsvolle Orte in den Hauptstädten zu eigen, wohingegen die Hauptstädte Zeichen des Gedenkens erhielten, die ihr Prestige weiter steigerten.

In Paris und in Berlin setzten sich demnach mit kleinen Unterschieden in Intensität und Form vergleichbare Entwicklungen durch. In den Hauptstädten gab es eine Zentralisierungswirkung, die ihnen eine besondere Bedeutung und allem, was sich dort befindet, eine außerordentliche Wahrnehmung verlieh. Für einzelne Gruppen war es deshalb attraktiv, an diesem weihevollen Ort ihr jeweiliges Gedenken zur Geltung zu bringen. Umgekehrt führte die Häufung von Zeichen des Gedenkens in den Hauptstädten dazu, deren nationale Bedeutung zu stärken, sodass einige städtische Charakteristika zu nationalen Attributen wurden. Schließlich konnte der Staat als Repräsentant bestimmter Formen des nationalen Gedenkens die lokalen Gedenkorte nutzen, um seinen Einfluss auf die Hauptstädte zu vergrößern.

Diese verschiedenen, hier nur skizzierten Verflechtungen lohnen die eingehendere Untersuchung auf der Grundlage der öffentlichen Debatten über nationale Kriegsdenkmäler, über die Pläne und gegebenenfalls deren Umsetzung.

\section{Frankreich: Diskussionen über das Nationaldenkmal}

Die Idee, ein Nationaldenkmal zu errichten, kam in Frankreich bereits während des Krieges auf; die im Parlament beratenen Vorhaben bezogen sich vornehmlich auf ein im Panthéon aufzubewahrenden goldenen Buch ${ }^{38}$. Im Lichte des Sieges trat eine Vielzahl neuer Vorschläge zu Tage. Einige stammten von Parlamentsmitgliedern, denen es darum ging, die Kriegsteilnehmer zu ehren und gleichzeitig den Sieg zu feiern. Angesichts der bevorstehenden Rückkehr der Truppen dachte man

aber nicht auf dieselbe Tradition pochen. Karl-Robert Schütze, Von den Befreiungskriegen bis zum Ende der Wehrmacht. Die Geschichte des Garnisonsfriedhofs am Rande der Hasenheide in Berlin-Neukölln, Berlin 1986.

38 Gesetzesvorlage [Proposition de loi] von Paul Escudier. Chambre des députés, 30.11.1915, Journal officiel de la République française, Chambre des députés, édition Documents parlementaires (JO Chambre/DP), S. 1336; Gesetzesvorlage von Jules Nadi. Chambre des députés, 14.12.1917, JO Chambre/DP, annexe n4074. 
zunächst an die Errichtung eines neuen Triumphbogens ${ }^{39}$ oder an die Nutzung des alten, der bereits auf dem Place de l'Étoile stand ${ }^{40}$. Zwar wurden auch neue Bauwerke und neue Formen von Denkmälern in Betracht gezogen ${ }^{41}$, doch gleichzeitig hielt man an der das Panthéon betreffenden Idee fest ${ }^{42}$.

Diese ersten, nach dem Krieg unterbreiteten Vorschläge zeigen, dass man eine monumentale Form des Gedenkens für erforderlich hielt, denn sie alleine war in der Lage, die Ehrung »in beständiger und offenkundiger Form ${ }^{43}$ « für künftige Generationen festzuhalten ${ }^{44}$. Zudem kam in den Augen der Abgeordneten allein Paris als Standort für ein derartiges Denkmal in Frage. Gewiss befanden sich der Arc de Triomphe auf dem Place de l'Étoile und das Panthéon in der Hauptstadt und erinnerten somit an ihre bereits lange währende symbolische Zentralität. Hinzu kam noch die Rolle, die Paris während des Krieges gespielt hatte: Die Stadt war »das Zentrum der Résistance gegen die Invasion der Barbaren und das Zentrum für die Gestaltung des Sieges ${ }^{45}$ «. Diese Aspekte griffen ineinander, um der Paris zukommenden Rolle noch mehr Gewicht zu verleihen und um zu unterstreichen, »dass es ganz normal sei, die ruhmvolle Aufgabe zu haben, der Nachwelt den materiellen und symbolischen Nachweis über das große Ausmaß unserer Aufopferung und über die strahlende Schönheit unserer Geschichte zu erbringen ${ }^{46}$.

Parallel zu den im Parlament diskutierten Vorschlägen erhielt der Ausschuss für künstlerische Arbeiten des Ministeriums für Bildung, Erziehung und schöne Künste eine Reihe von Entwürfen zu »Siegesdenkmälern«, die direkt von Privatpersonen stammten ${ }^{47}$. Künstler, die von der Absicht der Regierung, ein solches Denkmal zu errichten, Kenntnis erlangt hatten, brachten ihre Ansichten zu dem Thema spontan zur Geltung. Der größte Teil dieser Entwürfe galt Heldenstatuen, für die der Standort eher unerheblich war; andere Entwürfe waren gut durchdachte Gesamtkompositionen, die den Standort berücksichtigten. Auch hier wurden die den Arc de Triomphe und das Panthéon betreffenden Ideen oftmals wieder aufgegriffen, ohne sich gegenseitig auszuschließen ${ }^{48}$ und ohne dass es jemals nur darum ging, bereits bestehende Stätten anderweitig zu nutzen. Jene Entwürfe, die auf die Weiterverwendung des Triumphbogens auf dem Place de l'Étoile zielten, sahen

Gesetzesvorlage von Jean Locquin. Chambre des députés, 13.11.1918, JO Chambre/DP, S. 1929; Gesetzesvorlage von François Fournier. Chambre des députés, 26.11.1918, JO Chambre/DP, S. 1862.

40 Entschließungsantrag [Proposition de résolution] von Emile Constant. Chambre des députés, 19.11.1918, JO Chambre/DP, S. 1823.

41 Gesetzesvorlage von Georges Bonnefous. Chambre des députés, 31.12.1918, JO Chambre/DP, S. 2981.

42 Entschließungsantrag von Maurice Maunoury. Chambre des députés, 19.11.1918, JO Chambre/DP, S. 1823.

43 Gesetzesvorlage von Jean Locquin (wie Anm. 39).

44 Gesetzesvorlage von François Fournier (wie Anm. 39).

45 Gesetzesvorlage von Georges Bonnefous (wie Anm. 41).

46 Gesetzesvorlage von François Fournier (wie Anm. 39).

47 Archives nationales (AN), F/21/4770, dossier $2 \mathrm{~g}$.

48 Der Entwurf Balandier (Februar 1919) sah vor, den Lebenden einen Triumphbogen und den Toten ein Pantéon zu widmen. AN, F/21/4770, dossier $2 g$ 
seine Vervollständigung ${ }^{49}$, ja sogar seine Ausstattung mit einer grandiosen Krone $\operatorname{vor}^{50}$.

Auch wenn hier die Auswahl eines Standorts in Paris dominierte, so schloss dies die Möglichkeit nicht aus, ein Schlachtfeld in Nordfrankreich als Aufstellungsort zu favorisieren ${ }^{51}$. Das Problem jedoch war, dass es zahlreiche Schlachtfelder, aber nur eine französische Hauptstadt gab. Um die Vorzüge beider Standorte zu verbinden, stellten einige Entwürfe eine Verknüpfung zwischen verschiedenen Räumen her. So galt ein Entwurf einem Siegesdenkmal, das an drei Orten zugleich errichtet würde: in Paris, Strasbourg und Metz ${ }^{52}$. Diese Trias sollte verdeutlichen, dass das Elsass zusammen mit Lothringen unzweifelhaft zu Frankreich gehörte, das durch seine Hauptstadt vertreten wurde. Ein anderer Entwurf sah vor, eine Prachtstraße zu bauen, die Paris und das rund $40 \mathrm{~km}$ östlich gelegene Meaux - wo sich die Schlacht an der Marne abgespielt hatte - in einer geraden Linie miteinander verband, wobei Meaux bei dieser Gelegenheit Hauptstadt des Völkerbundes hätte werden können ${ }^{53}$. Die Parlamentarier befürworteten allerdings in Sachen Nationaldenkmal eher einen Standort in Paris, in unmittelbarer Umgebung der politischen Macht. Das sollte zwar nicht die Aufstellung anderer Denkmäler an anderen Orten verhindern, doch diese würden dann nicht den Anspruch auf den Status eines Nationaldenkmals erheben können.

Für das eigentliche Denkmal stellte sich nach wie vor die Frage, ob man sich auf bereits bestehende Monumente stützen oder wegen des Ausmaßes des Krieges und seiner Verluste etwas Neues erschaffen sollte. Im Laufe des Jahres 1919 mehrten sich die Stimmen zugunsten der zweiten Lösung mit der Begründung, dass die Gefallenen des Krieges etwas Besseres verdient hätten als die Aneignung irgendeines Denkmals aus der Vergangenheit. Während einige im Parlament nach wie vor Verfechter der Idee waren, den Arc de Triomphe auf dem Place de l'Étoile umzugestalten bzw. das Panthéon umzubauen, sprachen sich andere für die Errichtung eines passenden Denkmals aus, um »denjenigen ein Denkmal zu setzen, deren Andenken unser Vaterland und die Nachwelt niemals aufhören zu ehren; ein Denkmal, das auf sie zurückgeht und das ihnen allein gehört ${ }^{54}$.«

Während man sich im Verlauf des Krieges ein Gedenken vorstellte, das dem Größten, was man besaß (das Panthéon für die Toten, der Arc de Troimphe für die Lebenden), entsprechen sollte, so entwickelte sich in der Nachkriegszeit eine neue Auffassung: Der Krieg hatte die Vorstellungen, die man sich von ihm zuvor hatte machen können, weit übertroffen, und nun galt es, damit auf angemessene Weise

49 Der Entwurf Sionopel (Dezember 1918) sah vor, jeder der vier Ecken Skulpturengruppen und eventuell eine dreieckige Pyramide anzufügen; ein Teil der Champs-Élysées sollte den Namen »Allee des Großen Sieges« erhalten. Ebd.

50 Der Entwurf Massa (Dezember 1918) sah vor, vier gewaltige Bögen aus Stahlbeton zu errichten, die von den vier äußeren Ecken des Place de l'Étoile ausgingen und sich oberhalb des Arc de Triomphe trafen; an ihren Sockeln sollten vier Triumph-Säulen emporragen, während auf dem First des Gebäudes sich die Figur eines Frontsoldaten und ein gewaltiges Leuchtfeuer erhob. Ebd.

51 Entwurf Ducasble (März 1919), der vorsah, ein Siegesdenkmal der Alliierten auf der Ebene eines Gefechtsfelds zu errichten. Ebd.

52 Entwurf Deschamps (Juli 1919), ebd.

53 Entwurf Lataste (März 1919), ebd.

54 Rapport sur la proposition de loi relative à la commémoration et la glorification des morts pour la France. Sénat, 18.3.1919, Journal officiel de la République française, Chambre des députés, édition Documents parlementaires (JO Sénat/DP), S. 417. 
schöpferisch umzugehen. Der ursprüngliche Charakter des künftigen Denkmals und sein ungefährer Standort waren zwei Punkte, die theoretisch durch ein Gesetz vom 25. Oktober 1919 geregelt wurden: »Ein Nationaldenkmal für die auf dem Feld der Ehre gefallenen Helden des Ersten Weltkrieges wird in Paris oder in unmittelbarer Umgebung zur Hauptstadt errichtet ${ }^{55}$. Z Zwischen Beschluss und Umsetzung lag jedoch kein einfacher Weg, zumal weder der Ort noch die Form des künftigen Denkmals präzise festgelegt wurden.

In der Zwischenzeit beeinflussten die am 14. Juli 1919 organisierten Siegesfeiern die Gestaltung der Kriegserinnerung. Die Tatsache, dass sich ein Scheingrab, ein Kenotaph auf dem Place de l'Étoile befand, rückte zunächst wieder die Vorstellung von einem Denkmal der Trauer in den Vordergrund, während sich der Arc de Triomphe eher als bedeutender Ort des Kriegsgedenkens aufdrängte. Schließlich wurde im Parlament bereits im November 1918 insgeheim, und ab September 1919 etwas offener, erneut über die Idee gesprochen, einen Unbekannten Soldaten im Panthéon zu bestatten ${ }^{56}$. Der Streitkräfteausschuss befürwortete diese Idee im Oktober 191957, ohne dass jemand darin einen Widerspruch zu dem Gesetz sah, das die Errichtung eines neuen Denkmals vorsah. Durch die Beisetzung eines Unbekannten Soldaten schien sich die Streitfrage um das Nationaldenkmal also nicht lösen zu lassen, denn diese beiden Vorhaben entwickelten sich konkurrenzlos und parallel zueinander. Letztlich lag das Problem darin, dass sich die verschiedenen Vorhaben nicht gegenseitig ausschlossen, sodass die Frage nach einem wirklich unumstrittenen Nationaldenkmal weiterhin im Raum stand.

Auch wenn zwischen November 1919 und November 1920 hierzu keine Entscheidung fiel, fand die Idee der Beisetzung eines Unbekannten Soldaten doch quer durch die Presselandschaft Anklang. Die Tageszeitung »Le Journal « trat schon im September 1919 für das Vorhaben einer Beisetzung im Panthéon ein. Dann, im September 1920, nahm sich die konservative Presse des Themas an: »L'Action française « und »L'Intransigeant « unterstützten die Idee, einen Unbekannten Soldaten unter dem Arc de Triomphe beizusetzen; dank ihrer Pressekampagne schlossen sich ihnen die meisten der Veteranenverbände und ein großer Teil der öffentlichen Meinung $a^{58}$. Somit lehnten die Verfechter dieser Meinung das von der Regierung zur Sprache gebrachte Vorhaben ab, die Beisetzung im Panthéon im Rahmen einer gemeinsamen Gedenkfeier zu Ehren der Kriegsgefallenen und des Politikers Léon Gambetta durchzuführen.

Denn auch wenn die Idee, einen Unbekannten Soldaten beizusetzen, fast einhellige Zustimmung fand und sich der 11. November als Tag des Waffenstillstands als Datum für einen solchen Festakt geradezu aufdrängte, stieß das Zusammentreffen der Daten und eine eventuell am selben Tag stattfindende Feier zum fünfzigjährigen Bestehen der französischen Dritten Republik doch auf erheblichen Widerstand. Die Regierung stellte sich nämlich vor, das Herz von Gambetta, dem großen republikanischen Patrioten von 1870, an der Seite des Unbekannten Solda-

Gesetz vom 25.10.1919, Artikel 4, Journal officiel de la République française, édition Lois et Décrets (JO) vom 26.10.1919, S. 11910.

56 Entschließungsantrag von Maurice Maunoury. Chambre des députés, 19.11.1918, JO Chambre/DP, S. 1823; Entschließungsantrag von André Paisant. Chambre des députés, 12.9.1919, JO Chambre/DP, S. 2706.

57 Chambre des députés, 17.10.1919, JO Chambre/DP, S. 3169.

58 Jean-François Jagielski, Le soldat inconnu. Invention et postérité d'un symbole, Paris 2005, S. 70-73. 
ten, des zwischen 1914 und 1918 geopferten großen Patrioten, ruhen zu lassen, um den Bund zwischen der Republik und der Vaterlandsverteidigung zu symbolisieren. Von diesem Zeitpunkt an sorgten der noch auszuwählende Ort und die zu organisierende Feier für heftige Auseinandersetzungen. Die sozialistische Linke unterstützte die nationale Ehrung, für die sich das Panthéon ganz selbstverständlich anzubieten schien, und sie prangerte sämtliche Bestrebungen an, die Gedenkfeier in eine militärische Feier umzuwandeln, auf der die Führungsstäbe den von den Kriegsteilnehmern errungenen Sieg allein für sich beanspruchen würden. Die konservative Rechte lehnte eine Beisetzung im Panthéon - an dem Ort eines ihr fremden staatsbürgerlichen Totenkultes - kategorisch ab; sie gab dem Arc de Triomphe den Vorzug, dessen Ruhm ihr geeigneter erschien.

Die ursprüngliche Idee war in der Tat die Beisetzung des französischen Unbekannten Soldaten im Panthéon, einem Ort, der speziell für die "großen Männer « bestimmt war, denen das Vaterland seine Anerkennung aussprach. So lautet die Inschrift auf dem Giebel des Gebäudes: »Aux grands hommes la patrie reconnaissante «. Doch obwohl das Bauwerk in den Inszenierungen der Dritten Republik regelmäßig genutzt wurde, war es keine populäre Stätte: Es war ein finsterer, unzugänglicher Ort, der kaum in der Lage war, allgemeine Begeisterung hervorzurufen. Außerdem war der staatsbürgerliche Kult, für den das Panthéon genutzt wurde, durch die Französische Revolution geprägt, wodurch es wenig konsensfähig war ${ }^{59}$. Der Arc de Triomphe hingegen ist ein offener, zugänglicher Ort, der die dynamischen Stadtviertel des Pariser Westens überragt. Zu spät fertiggestellt, um den Ruhm seines Initiators Napoleon wahrhaft zu verkörpern, stand er gewissermaßen für eine neue, dem Bauwerk angemessene Verwendung zur Verfügung ${ }^{60}$. Dennoch wies dieses Bauwerk eine stark ausgeprägte militärische und nationalistische Bedeutung auf. Dort ein Grabmal des Unbekannten Soldaten zu errichten lief darauf hinaus, in ihm eher einen »Helden « als einen »großen Mann« zu sehen. Während die einen die Republik in den Vordergrund des Kriegsgedenkens stellten, hoben die anderen die militärische Ehre hervor.

Angesichts der großen Bedeutung des Standortes fällt auf, dass diese Frage so spät geklärt wurde. Erst am 6. November 1920 befasste sich der Finanzausschuss des Parlaments mit einem Gesetzentwurf, der vorsah, am zweiten Jahrestag des Waffenstillstands die sterblichen Überreste eines anonymen Soldaten ins Panthéon zu überführen. Der Finanzausschuss äußerte sich positiv über die Zuteilung der von der Regierung beantragten 300000 Francs. In der Absicht, die öffentliche Meinung wiederzugeben, forderte er dann außerhalb seiner rein technischen Rolle bei der Bewilligung der finanziellen Mittel die Beisetzung des Unbekannten Soldaten unter dem Arc de Triomphe ${ }^{61}$.

Obwohl die Fristen sehr kurz waren, wurde dieser Punkt am 6. November im Ministerrat besprochen, und Pensionsminister André Maginot brachte eine mögliche Lösung vor: Durch eine geringfügige Änderung des vorgesehenen Programms könne der Unbekannte Soldat nach der Gedenkfeier im Panthéon bis zu seiner endgültigen Beisetzung unter dem Arc de Triomphe zwischenzeitlich in ein proviso-

59 Mona Ozouf, Le Panthéon. L'Ecole normale des morts. In: Les lieux de mémoire (wie Anm. 4), S. 155-177.

60 Antoine Prost, Les anciens combattants et la société française, vol. 3, Paris 1977, S. 36.

${ }^{61}$ Chambre des députés, 8.11 .1920 (séance extraordinaire), JO Chambre/Débats, S. 3179. 
risches Grab vor Ort überführt werden ${ }^{62}$. So wurde ein geänderter Gesetzentwurf noch am selben Tag ins Parlament eingebracht. Genehmigt wurden diese Änderungen vom Bildungsausschuss, der den Wortlaut des Gesetzentwurfs neu abfasste. Die Lesung des Gesetzes konnte nun nach dem durch die Regierung erzielten Dringlichkeitsverfahren beginnen; die große Eile minderte allerdings nicht die Heftigkeit der geführten Debatte ${ }^{63}$.

Auf die am 8. November 1920 im Parlament geführte Debatte wurde bereits eingegangen ${ }^{64}$. An dieser Stelle genügt es festzuhalten, dass der Ort der Beisetzung des Unbekannten Soldaten weitgehend im Fokus der hitzigen Auseinandersetzungen stand. Schon bei der Lesung des 1. Artikels des Gesetzentwurfs, der vorsah, dem Unbekannten Soldaten die Ehren des Panthéons zukommen zu lassen, unterstrich Léon Daudet, der Wortführer der Nationalisten, seine Ablehnung mit dem Ausruf: »Am Arc de Triomphe«. Paul Escudier, der zum demokratisch-republikanischen Bündnis gehörte, erwiderte daraufhin: »Im Panthéon«. Auf Anhieb zeichneten sich zwei Lager ab, die sich gegenseitig solange ins Wort fielen, bis der Vorsitzende die Sitzung unterbrach. Artikel 2, der den Arc de Triomphe für die endgültige Beisetzung vorsah, entfachte den Streit erneut. Ferdinand Buisson als Vertreter der Radikalen verteidigte den ursprünglichen Gedanken der Regierung: Dem Unbekannten Soldaten das Panthéon zu verwehren hieße, jemandem ohne Dienstgrad die höchste Ehre zu verweigern, wodurch außerdem die Dualität zwischen der im Panthéon vertretenen Nation und der am Arc de Triomphe dargestellten Armee wiederhergestellt wäre. Daudet setzte seinen Protest wie folgt fort: »Das Panthéon wurde von Emile Zola in den Schmutz gezogen!«, noch bevor sich der Royalist Armand de Baudry d'Asson seinerseits für den Arc de Triomphe stark machte. Der republikanische Linke André Paisant jedoch, der im Juli 1920 die Gesetzesvorlage zur Beisetzung eines anonymen Soldaten im Panthéon eingebracht hatte, trat nun ohne Weiteres für die Option Arc de Triomphe ein. Buisson seinerseits zog seinen Antrag auf Streichung von Artikel 2 zurück. Schließlich griff der progressive Katholik Mars Sangnier in die Debatte ein und versuchte zu beschwichtigen. Er weigere sich zwar, seine Meinung zum symbolischen Wert der jeweils in Betracht gezogenen Orte kundzutun, da er aber festgestellt habe, dass das Panthéon die Geister scheide, sehe er darin eine ausreichende Begründung dafür, den Unbekannten Soldaten, dessen politische Zugehörigkeit niemand kenne, dort nicht zu bestatten. Die Wortgefechte der Panthéon-Befürworter versiegten mit dieser Intervention zwar nicht vollständig, doch die einzelnen, zur Abstimmung gebrachten Artikel des Gesetzes wurden letztlich beschlossen.

Der Entwurf wurde umgehend dem Senat vorgelegt, der ihn mit äußerster Dringlichkeit behandelte. Hier war man gewillt, sich zu einigen. Die Senatoren vom linken Flügel, die durch die Stimme von Paul Strauss den Wunsch äußerten, die Gleichwertigkeit der beiden Gedenkfeiern vom 11. November - die der Republik und die des Waffenstillstands - sicherzustellen, forderten eine Änderung des für den Trauerzug vorgesehenen Weges, damit nach der Gedenkfeier im Panthéon das Herz von Léon Gambetta die sterblichen Überreste des Unbekannten Soldaten bis zum Arc de Triomphe begleiten konnte. Dadurch, dass die Regierung diese 


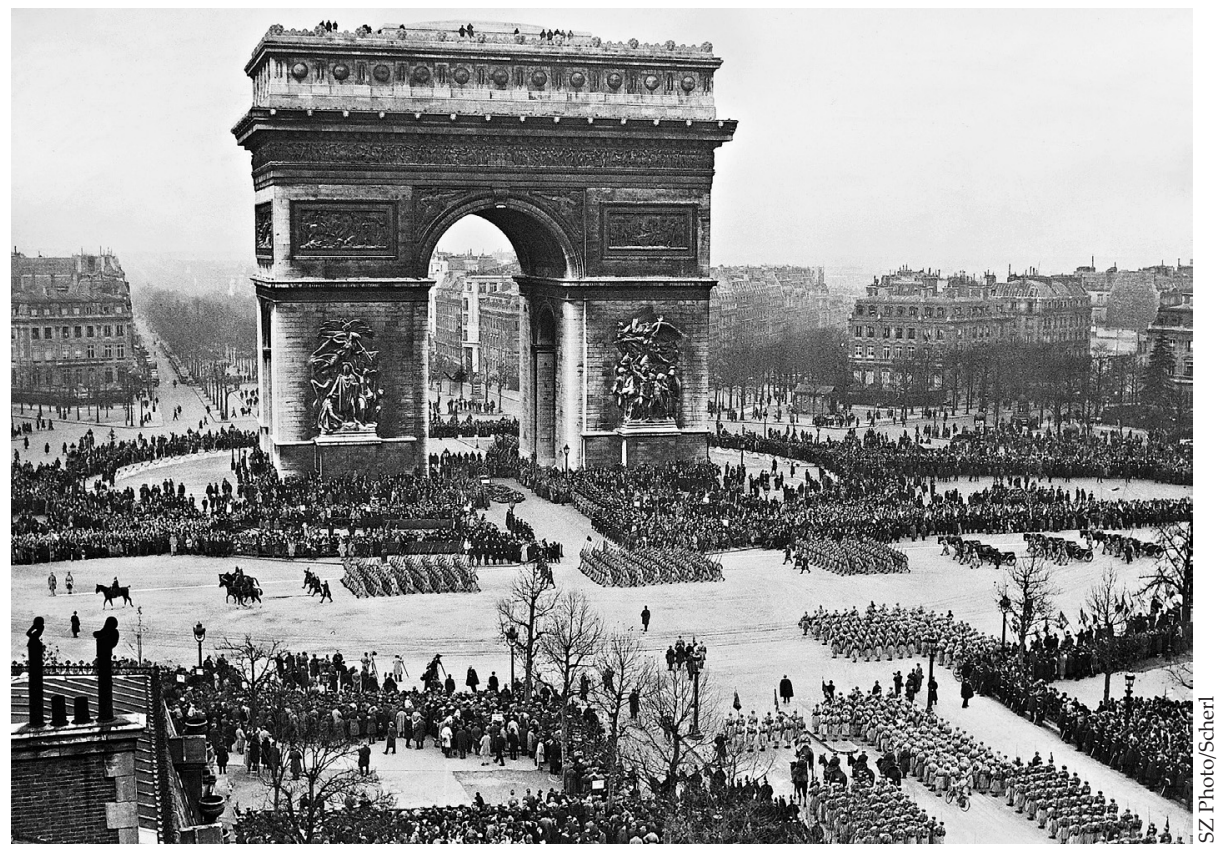

Abb. 1: Feierlichkeiten zum Tag des Waffenstillstandes am Grabmal des Unbekannten Soldaten unter dem Arc de Triomphe, 1. November 1931. Nach der Kranzniederlegung marschieren französische Truppen in Formation.

Verpflichtung einging, wurde der gesamte Gesetzentwurf einstimmig angenommen $^{65}$.

Die Ehrerweisung wurde also schließlich aufgeteilt: Das Herz von Gambetta wurde ins Panthéon überführt, während die sterblichen Überreste des Unbekannten Soldaten unter dem Arc de Triomphe bestattet wurden. Die Gedenkfeier war dennoch bemüht, eine dauerhafte Bindung zwischen den beiden Aspekten dieser Ehrung beizubehalten. Am Abend des 10. November wurde der aus Verdun eingetroffene Leichnam des Unbekannten Soldaten für eine nächtliche Totenwache zum Place Denfert-Rochereau, ganz in die Nähe des Herzens von Gambetta, gebracht. Am nächsten Tag waren der Unbekannte Soldat und Gambetta Teil desselben Trauerzuges. Dieser begab sich zunächst zum Panthéon. Dort stoppte er für die Dauer einer Rede des Präsidenten der Französischen Republik, Alexandre Millerand, der die Republik und ihre herausragenden Persönlichkeiten mit dem Unbekannten Soldaten verknüpfte. Dann setzte der Trauerzug seinen Weg zum Arc de Triomphe fort, wo die Menschen eine Schweigeminute einlegten. Das Herz von Gambetta kehrte danach alleine zum Panthéon zurück, während der Unbekannte Soldat bis zu seiner Beisetzung am 28. Januar 1921 vor Ort blieb.

Seit diesem Tag, und obwohl der Arc de Triomphe nirgendwo offiziell als nationales Kriegsdenkmal bezeichnet wurde, war keine Rede mehr davon, ein weiteres großes Nationaldenkmal zu errichten. Das Gesetz vom 25. Oktober 1919, das ausdrücklich die Errichtung eines Ehrenmals in Paris vorsah, wurde schließlich 
ziemlich frei ausgelegt, um in der Errichtung des Grabmals des Unbekannten Soldaten einen Abschluss zu finden.

Wie die Kirche verzichtete folglich auch der Staat darauf, ein großes architektonisches Bauwerk zu errichten. Wahrscheinlich haben bei diesem beiderseitigen Verzicht die wirtschaftlichen Schwierigkeiten der Nachkriegszeit eine Rolle gespielt. Insofern könnte das nationale Kriegsdenkmal mit den lokalen Ehrenmälern um Finanzmittel konkurriert haben. Zwar wurde das Prinzip der Ehrenmäler im gleichen Zuge, nämlich mit dem Gesetz vom 25. Oktober 1919, beschlossen ${ }^{66}$. Doch das Haushaltsgesetz vom 31. Juli 1920, das den Satz der Subventionen festlegte, die der Staat den Gemeinden für die Errichtung ihrer Ehrenmäler bewilligen musste, sah auf Anhieb eine Subvention von 4 bis 15 Prozent der in den kommunalen Haushaltsplänen veranschlagten Finanzmittel sowie eine ergänzende Subvention in Höhe von 1 bis 11 Prozent dieser Mittel vor ${ }^{67}$. Die Kosten dieser Maßnahme beliefen sich auf Millionen und gingen weit über die für die Errichtung des Grabmals des Unbekannten Soldaten bereitgestellte Summe von 300000 Francs hinaus $^{68}$. Während sich die lokalen Ehrenmäler, denen der Staat seine Unterstützung zugesagt hatte, in den Gemeinden mehrten, ermöglichte es die starke Symbolik des Unbekannten Soldaten, eine zentrale Gedenkstätte für die im Krieg Gefallenen zu geringeren Kosten zu errichten.

Tatsächlich erlangte der neu gestaltete Arc de Triomphe den Rang als nationales Kriegsdenkmal. Es ist der allen Franzosen zugängliche Ort der Andacht, der Ort der offiziellen Gedenkfeiern am 11. November, der Ort der Ehrerweisungen durch ausländische Besucher. Von zwei Projekten, die eine ganz unterschiedliche Entwicklung durchlaufen hatten, setzte sich also das Projekt »Unbekannter Soldat « gegenüber dem Projekt »Nationaldenkmal« durch, weil ersteres gleichzeitig eine Lösung für letzteres bot. Von diesem Zeitpunkt an erhob keines der zahlreichen anderen, noch nach dem 11. November 1920 in Frankreich erbauten Denkmäler den Anspruch, sich mit dem Arc de Triomphe messen zu wollen. Einerseits verhinderte der frühe Erfolg des Symbols des Unbekannten Soldaten und seiner Grabstätte die Errichtung einer wirklich konkurrenzfähigen Stätte; andererseits ermöglichte die fehlende Konkurrenz die Nutzung des Grabmals unter dem Arc de Triomphe als einziges nationales Kriegsdenkmal und so dessen Vollendung.

\section{In Deutschland: Debatten über ein Reichsehrenmal}

Der Gedanke, ein nationales Ehrenmal zu errichten, war auch in Deutschland schon in den Kriegsjahren aufgetaucht. Im Herbst 1916 schlugen Privatleute vor, auf einer Anhöhe in Berlin eine Kathedrale zu errichten, die alle Bauwerke der Welt über-

Gesetz vom 25.10.1919 (wie Anm. 55). Artikel 1 und 2 des Gesetzes betreffen die Register, welche die Namen der Toten enthalten und die im Panthéon aufbewahrt werden, Artikel 3 das Goldene Buch, das in jeder Gemeinde vorliegen soll, Artikel 4 das Nationaldenkmal, das in Paris errichtet werden soll, Artikel 5 die Subventionen, welche die Kommunen für die Ehrung der für das Vaterland Gefallenen erhalten.

67 Haushaltsgesetz vom 31.7.1920, Artikel 81, JO vom 1.8.1920, S. 10940. Die Abstimmung über den entsprechenden Kredit wurde auf eine spätere Sitzung verschoben.

68 Gesetz vom 9.11.1920, JO vom 13.11.1920, S. 18106. 
ragen und in der die Asche aller in fremder Erde liegenden deutschen Soldaten gesammelt werden sollte ${ }^{69}$. Die Vorschläge für ein nationales Ehrenmal waren zwar ehrgeizig, zielten aber nicht alle auf diese Heldenverehrung ab. Einer sah vor, in Anlehnung an die Gartenstadtbewegung eine Friedensstadt zu bauen, die in Erinnerung rufen sollte, wofür die Deutschen Opfer gebracht hatten, und die Wohnungen für die Soldaten bieten sollte ${ }^{70}$. Diese Vorschläge zeigen bereits, welche verschiedenen Möglichkeiten es gab, sozial orientierte Denkmäler, Architekturprojekte oder auch Kultbauten zu errichten, auch wenn dies alles erst nach Kriegsende umgesetzt wurde.

Das Ende des Krieges ging allerdings nicht mit einer Zunahme der Projekte einher. Nach der Niederlage schien die Frage sogar aus dem Blickfeld der Öffentlichkeit zu verschwinden, denn Ausgaben für Ehrenmäler standen weit unten auf der Prioritätenliste, und über die Kriegserinnerung ließ sich nur schwer Einigkeit erzielen. Die deutsche Regierung musste erst den Anstoß dazu geben, dass dieses Thema nach mehreren Jahren wieder aktuell wurde ${ }^{71}$.

Während der Vorbereitungen zum zehnten Jahrestag des Kriegsbeginns schlug Außenminister Gustav Stresemann vor, die Feiern am 3. August 1924 mit der Grundsteinlegung für eine Ehrensäule für die Kriegsgefallenen zu begehen ${ }^{72}$. Aber die Regierung wurde umgebildet, sodass die Modalitäten für eine solche Maßnahme nicht rechtzeitig ausgearbeitet wurden. Am 3. August riefen Reichspräsident Friedrich Ebert und Reichskanzler Wilhelm Marx gleichwohl zur Errichtung eines Ehrenmals für die Kriegsgefallenen auf, denn ein solches Werk sei eine moralische Pflicht und solle durch Spenden finanziert werden. Es wurde aber nichts darüber gesagt, um welche Art von Ehrenmal es sich handeln, welche Form es haben oder wo es stehen sollte. Auch waren bei Weitem nicht alle dafür, schon aus Kostengründen $^{73}$. Zudem lagen die politischen Prioritäten woanders, sodass der am 16. Oktober 1924 von der Länderkammer, dem Reichsrat, gegründete »Aus-

Zusammenstellung der dem Reichsministerium des Innern bekannt gewordenen Vorschläge zur Errichtung eines Nationaldenkmals für die Gefallenen im Weltkriege, November 1925, BArch, R 32/353.

70 Hans Kampffmeyer, Friedenstadt. Ein Vorschlag für ein deutsches Kriegsdenkmal, Karlsruhe 1918.

71 Zur Geschichte des Reichsehrenmals vgl. Wolfgang Ribbe, Flaggenstreit und Heiliger Hain. Bemerkungen zur nationalen Symbolik in der Weimarer Republik. In: Aus Theorie und Praxis der Geschichtswissenschaft. Festschrift für Hans Herzfeld zum 80. Geburtstag. Hrsg. von Dietrich Kurze, Berlin 1972, S. 175-188; Peter Bucher, Die Errichtung des Reichsehrenmals nach dem Ersten Weltkrieg. In: Jahrbuch für westdeutsche Landesgeschichte, 7 (1981), S. 359-386; Meinholz Lurz, Kriegerdenkmäler in Deutschland, Bd 4: Die Weimarer Republik, Heidelberg 1985, S. 47-100; Benjamin Ziemann, Die deutsche Nation und ihr zentraler Erinnerungsort. Das »Nationaldenkmal für die Gefallenen im Weltkriege « und die Idee des »Unbekannten Soldaten « 1914-1935. In: Krieg und Erinnerung. Fallstudien zum 19. und 20. Jahrhundert. Hrsg. von Helmut Berding, Klaus Heller und Winfried Speitkamp, Göttingen 2000, S. 67-91.

72 Ministerbesprechung vom 24.5.1924, Akten der Reichskanzlei (ARK). Die Kabinette Marx I und II (1923-1925), 2 Bde. Bearb. von Günter Abramowski. Hrsg. für die Historische Kommission bei der Bayerischen Akademie der Wissenschaften von Karl Dietrich Erdmann und für das Bundesarchiv von Wolfgang Mommsen (bis 1972) unter Mitwirkung von Walter Vogel (bis 1978) und Hans Booms, Boppard a.Rh. 1973, hier Bd 1, S. 663.

73 Reichsminister des Innern, Pressestimmen zu den Gedanken der Errichtung eines Nationaldenkmals für die Gefallenen im Weltkrieg, 11.11.1924, BArch, R 32/353. 
schuss für die Errichtung eines Nationaldenkmals für die Gefallenen im Weltkrieg « erst am 21. November 1925 zum ersten Mal zusammentrat ${ }^{74}$.

Bei dieser Sitzung verglich der Ausschuss 64 ganz unterschiedliche Projekte, die nicht immer an einen bestimmten Ort gebunden waren ${ }^{75}$. Bei zehn Projekten war Berlin als Standort vorgesehen; zu nennen sind hier insbesondere das von der Stadtverwaltung geplante Ehrenmal im Bellevuepark und das Projekt der preußischen Regierung, die das von Karl Friedrich Schinkel zu Beginn des 19. Jahrhunderts errichtete Gebäude der Neuen Wache umbauen wollte. Aber es gab auch ehrgeizige Projekte, die außerhalb der Hauptstadt entstehen sollten. Die Stadt Bonn sprach sich für den Bau einer Rheinbrücke aus, der Kölner Oberbürgermeister Konrad Adenauer war dafür, das Grabmal des Unbekannten Soldaten in unmittelbarer Nähe zum Kölner Dom errichten zu lassen, und die Kriegervereine des Kyffhäuserbunds wollten eine Ehrenhalle in die Felswände des Kyffhäusers im Harz gegraben haben. Andere Vorschläge enthielten ganz verschiedene Standorte; zu nennen sind hier vor allem diejenigen, die bereits bestehende Denkmäler in Goslar (Kaiserpfalz) oder im Teutoburger Wald (Hermannsdenkmal) oder auch Naturdenkmäler im Rheintal oder im Wesertal betrafen. Der antirepublikanische »Stahlhelm « empfahl schließlich, im thüringischen Bad Berka nahe Weimar einen Heiligen Hain anzulegen. Die Veteranen dachten dabei an eine Waldfläche, die von einer hohen, von vier monumentalen Toren durchbrochenen Mauer umgeben war, die den Ort abschirmen und eine Atmosphäre des Gedenkens schaffen sollte, noch bevor man zu dem eigentlichen Denkmal gelangte: einer Art Gruft mit einem Sarkophag.

Angesichts dieser Möglichkeiten musste man einerseits entscheiden, ob man ein bestehendes Denkmal neu nutzen oder lieber ein neues Denkmal schaffen wollte, und sich andererseits für die Art des Standorts entscheiden, wobei man die Wahl zwischen Stadt und Natur hatte. Ohne über diese Fragen zu entscheiden, traf der Ausschuss eine erste Auswahl, die noch sehr unterschiedliche Vorschläge umfasste: den Bau einer Rheinbrücke, das Graben einer Ehrenhalle in den Kyffhäuser, die Anlage eines Heiligen Hains, dessen Standort noch zu bestimmen war, oder den Umbau der Neuen Wache in Berlin. Die Behörden wiesen darauf hin, dass sie immer noch auf Vorschläge aus der Bevölkerung warteten und die besten Ideen aufnehmen wollten. Auf der Grundlage dieser Befragung sollte der Reichskunstwart Edwin Redslob in Zusammenarbeit mit renommierten deutschen Künstlern die endgültige Entscheidung vorbereiten.

Nun herrschte zwar Einigkeit darüber, dass das geplante Denkmal möglichst wenig kosten und durch Spenden finanziert werden sollte. Doch schnell bildeten sich die Fronten zwischen den Anhängern der wesentlichsten Projekte heraus, die verschiedene und manchmal unvereinbare Vorstellungen darüber entwickelten, was ein Nationaldenkmal ausmachte. Für die einen konnte ein solches Denkmal nur an einem zentralen Ort stehen, wo es gut sichtbar war und von vielen besucht werden konnte, und dafür bot sich die Hauptstadt bestens an. Andere hingegen waren der Meinung, ein solches Denkmal könne nicht in der Stadt und schon gar

Der Reichsrat führte im Reichsinnenministerium die Vorschläge zusammen und hatte seinerseits die Federführung. BArch, R 32/353.

75 Zusammenstellung der dem Reichsministerium des Innern bekannt gewordenen Vorschläge zur Errichtung eines Nationaldenkmals für die Gefallenen im Weltkriege, November 1925, BArch, R 32/353. 
nicht in Berlin stehen, denn die für das Gedenken notwendige Ruhe lasse sich nur in der Natur finden. Vor allem dem »Stahlhelm « gelang es, die großen Kriegervereine, den »Reichsbanner Schwarz-Rot-Gold «, den »Reichsbund jüdischer Frontsoldaten « und den »Kyffhäuserbund «, für seine Idee zu gewinnen - eine beispiellose Einigung von ideologisch weit auseinander liegenden Verbänden.

Der »Ausschuss für die Errichtung eines Nationaldenkmals für die Gefallenen im Weltkrieg « traf sich erneut am 16. Januar 1926 und sprach sich für einen Umbau der Neuen Wache in Berlin aus, wofür er die Unterstützung des neuen Reichspräsidenten (und ehemaligen Generalfeldmarschalls) Paul von Hindenburg erhielt $^{76}$. Wahrscheinlich lässt sich darin genau wie in Paris, wenn auch zu einem späteren Zeitpunkt, das Bedürfnis der Führung nach einer institutionellen Gedenkstätte in der Hauptstadt erkennen. Diese Entscheidung stellte außerdem die preuBische Regierung zufrieden, die es gerne sah, dass Berlin damit als politisches Zentrum gestärkt wurde und dass ihr Wort in dieser Angelegenheit dann mehr gelten würde.

Aber schon im folgenden Monat führte der Druck der Kriegervereine zu einer Umkehrung dieser Tendenz ${ }^{77}$ : Redslob sprach sich für das Vorhaben des Heiligen Hains in Thüringen aus; die Mehrheit des Ausschusses und nun auch Hindenburg folgten dieser Auffassung. Doch noch bevor eine Entscheidung getroffen wurde, änderte sich die Lage erneut.

Unter den vielen Vorschlägen, die weiterhin im Reichsministerium des Innern eingingen, erweckte der Plan des Umbaus einer Rheininsel zu einer Toteninsel besonderes Interesse. Der breitere Teil der Insel sollte als Sammelplatz für die sterblichen Überreste dienen. Durch eine mit Gedenktafeln geschmückte Allee war ein Zugang zu einem Ehrenhof geplant, an dessen hinterem Ende sich ein Sarkophag mit einem Stahlhelm darauf über einer Gruft erheben sollte ${ }^{78}$. Dieses Vorhaben vereinte jene, die sich Sorgen über die Zukunft der besetzten Gebiete machten und die darin eine Möglichkeit sahen, auf deren Lage aufmerksam zu machen. Um ihre Chancen beim Ausschuss zu erhöhen, bemühten sich die politisch Verantwortlichen der Rheinprovinz zuerst, die Kriegervereine für sich zu gewinnen. Dann ließen sie ihre persönlichen Beziehungen spielen, um direkten Einfluss auf die Reichsregierung zu nehmen ${ }^{79}$.

Nach einer Reihe von Besuchen an den etwa zehn möglichen Standorten für das Ehrenmal und einer genauen Beurteilung der einzelnen Pläne blieb der Ausschuss am 10. Juli 1926 bei seiner Entscheidung für den Heiligen Hain und legte Bad Berka als Standort fest ${ }^{80}$. Bei einer schnellen Entscheidung der Reichsregierung hätte am 3. August 1926 der Beginn der Arbeiten bekanntgegeben werden

76 Niederschrift über die Sitzung des Ausschusses zur Errichtung eines Nationaldenkmals für die Gefallenen im Weltkrieg am 16.1.1926 im Reichministerium des Innern, BArch, R 32/353.

77 Niederschrift über die Sitzung des Ausschusses zur Errichtung eines Nationaldenkmals für die Gefallenen im Weltkrieg am 11.3.1926 im Reichministerium des Innern, BArch, R 32/353.

78 Karl Wach und Richard Klapheck, Das Reichsehrenmal für unsere Gefallenen. Die Toteninsel im Rhein, Düsseldorf 1926.

79 Das Rheinland war damals eine Provinz des Freistaates Preußen. Als solche verfügte sie über eigene Provinz-Institutionen, deren wichtigste politische Verwaltungseinrichtungen in Koblenz und Düsseldorf lagen.

80 Redslob, Denkschrift über eine Ehrung der im Weltkrieg Gefallenen, 12.7.1926, BArch, R 32/353a. 
können. Aber die Regierung stand unter dem starken Druck der Anhänger eines Ehrenmals am Rhein bzw. eines Umbaus der Neuen Wache und wollte sich deshalb noch nicht endgültig festlegen ${ }^{81}$.

Die Anhänger des Rheinprojekts profierten von dieser Verschiebung der Entscheidung und organisierten sich in einem »Ausschuss für das Reichsehrenmal am Rhein « unter dem Vorsitz von Johannes Horion, dem populären Landeshauptmann der Rheinprovinz. Sie starteten eine umfangreiche Lobbyarbeit, um jeden Plan eines Ehrenmals an einem anderen Ort als dem Rheinufer zu unterbinden. Die Pressekampagnen in der Rheinprovinz sorgten für großen Wirbel ${ }^{82}$. Aus Sorge, einen Proteststurm gegen ein doch als einvernehmlich geplantes Projekt heraufzubeschwören, beschloss die Reichsregierung im Oktober 1926, sich mit den Verantwortlichen der Koalitionsparteien auf einen Standort zu einigen, wodurch sich der Entscheidungsprozess de facto noch länger verzögerte ${ }^{83}$. Es kamen vor allem drei Standorte für drei Arten von Projekten mit ganz verschiedenen Grundlagen in Betracht.

Der Plan des Heiligen Hains war mit einem entsprechenden Standort, verbunden - dem Wald. Seit den Anfängen der Nationalbewegung symbolisierte dieser den Ursprung, die Natur und die Kraft der Deutschen ${ }^{84}$. Das Gefallenengedenken dieser heiligen Kuppel der Natur anzuvertrauen hieß, es mit einer zeitlosen germanischen Symbolkraft aufzuladen. Da das Nationaldenkmal dank des Waldes als ein Ort zum Kraftschöpfen gedacht war, wurde aus der Treue gegenüber den Toten ein Programm nationaler Erholung. Diese Art der Ehrung war jedoch so abstrakt, dass man damit deutliche Aussagen zur Staatsform, zu den Ursachen und zum Ausgang des Krieges oder zum Sinn, den man dem Tod der Soldaten geben sollte, vermeiden konnte. Auf diese Weise konnten politische Gegensätze überbrückt werden, weshalb die wichtigsten Kriegervereine diese Art des Kompromisses aus Vernunftgründen annahmen. Thüringen wurde wegen seiner zentralen Lage »im Herzen Deutschlands « ausgewählt, um regionale Spannungen zu überwinden. Manche wiesen außerdem auf die Nähe Bad Berkas zu Weimar hin, der Stadt Goethes und der republikanischen Verfassung. Doch nicht alle waren mit dieser beschwichtigenden Lösung einverstanden. Die radikalen Nationalisten kritisierten die unauffällige Form und die abseitige Lage dieses Heiligen Hains; die Franzosen hätten ihr Nationaldenkmal schließlich auch nicht in einem Wald in der Auvergne errichtet $^{85}$. Mit einem solchen Projekt ließe sich der Nationalstolz kaum zum Ausdruck bringen; es sei, argwöhnten sie, wohl nur deshalb ausgewählt worden, weil es keinen Missfallen bei den Siegern hervorrufen sollte.

81 Kabinettsitzung vom 19.7.1926, ARK, Die Kabinette Marx III und IV (1926-1928), 2 Bde. Bearb. von Günter Abramowski. Hrsg. für die Historische Kommission bei der Bayerischen Akademie der Wissenschaften von Karl Dietrich Erdmann und für das Bundesarchiv von Wolfgang Mommsen (bis 1972) unter Mitwirkung von Walter Vogel (bis 1978) und Hans Booms, Boppard a.Rh. 1988, hier Bd 1, S. 62. Rheinische und preußische Amtsträger taten sich zusammen, um das Projekt von Bad Berka zum Scheitern zu bringen. BArch, R 43 I/714.

82 Reichsministerium des Innern, Pressenstimmen, BArch, R 32/361.

83 Kabinettssitzung vom 22.10.1926, ARK, Kabinett Marx III und IV (wie Anm. 81), Bd 1, S. 263.

84 Ziemann, Die deutsche Nation (wie Anm. 71), S. 73.

85 Aufruf der Pressestelle für die Errichtung des Reichsehrenmales im Rhein, 14.9.1927, BArch, R 1501/125800. 
Während die Anhänger des Heiligen Hains den Standort Großstadt und die damit verbundenen Machtspielchen bewusst mieden, gab es auch zahlreiche Stimmen, die ein Nationaldenkmal in der Hauptstadt forderten ${ }^{86}$. Der Vergleich der deutschen Situaton mit der fortgeschrittenen Lage im Ausland tauchte in der Befürwortung des Standorts Berlin immer wieder auf: »Die anderen Völker hätten ihr Gefallenendenkmal sämtlich in der Hauptstadt ihres Landes errichtet. Nur in Deutschland sträube man sich gegen diese Selbstverständlichkeit ${ }^{87}$. Das Projekt fand bei der Reichsregierung und der Reichswehr große Unterstützung. Die Reichswehr schlug beispielsweise vor, vor dem Brandenburger Tor ein Ehrenmal für die im Weltkrieg gefallenen Soldaten der Armee und der Marine zu errichten. Der beste Beweis dafür, dass der Standort geeignet war, lag ihrer Meinung nach in dem bereits bestehenden vorläufigen Ehrenmal für die Toten des »Reichsbanners Schwarz-Rot-Gold « im Weltkrieg, das zum zehnten Jahrestag der Weimarer Verfassung an dieser Stelle errichtet worden war ${ }^{88}$. Allerdings war Berlin traditionell in erster Linie die Hauptstadt Preußens und dann erst die Reichshauptstadt, weshalb zahlreiche deutsche Regionen oder Länder auf ihrer Selbstständigkeit und ihren Privilegien beharrten und nur schwer anerkennen wollten, dass Preußen auf die eine oder andere Weise das Reichsehrenmal für sich beanspruchte.

Mit dem Plan eines Ehrenmals am Rheinufer wurde auf ein anderes Symbol der deutschen Identität gesetzt: eine Darstellung des Vaterlandes, die sich auf die germanische Mythologie berief ${ }^{89}$. Im Gegensatz zum Wald, der als Zufluchtsort erschien, war der Rhein, der deutsche »Schicksalsstrom«, ein Ort der Bewegung und des Lebens. Dort wurden Ende des 19. Jahrhunderts die meisten Nationaldenkmäler gebaut ${ }^{90}$. Durch diese Faktoren erhielt der Standort angesichts der Errichtung eines nationalen Erinnerungsortes eine offensive Konnotation. Der Rhein lag nicht nur relativ nahe an den Kampffronten, sondern hatte vor allem auch eine allgemeine Bedeutung für Deutschland: »Es ist oft genug gesagt worden und mit Recht gesagt worden, dass, was Paris für Frankreich, dass das der Rhein für Deutschland ist ${ }^{91}$." Die Rheinprovinz wurde so zum Herzen des Deutschen Reiches stilisiert, aber dieselben Anhänger, die diese Pläne für ein Ehrenmal am Rhein verfochten, drohten mit Separatismus für den Fall, dass das Ehrenmal in einer anderen Region Deutschlands errichtet würde. Schließlich zeigten sich in dieser Haltung zwar tatsächliche föderalistische Spannungen, aber dahinter lagen lokale wirtschaftliche Interessen, die kaum zu übersehen waren. Bei dem Plan eines Ehrenmals in Mariannenau zum Beispiel führte der Inhaber des gegenüberliegenden Restaurants die Gruppe der Förderer $a^{92}$.

89 Lucien Febvre, Le Rhin. Histoire, mythes et réalités, Paris 1931.

90 Reinhard Alings, Monument und Nation, das Bild vom Nationalstaat im Medium Denkmal. Zum Verhältnis von Nation und Staat im deutschen Kaiserreich 1871-1918, Berlin 1996; Charlotte Tacke, Denkmal im sozialen Raum. Nationale Symbole in Deutschland und Frankreich im 19. Jahrhundert, Göttingen 1995.

91 Aufruf der Pressestelle für die Errichtung des Reichsehrenmales im Rhein, 7.9.1927, BArch, R 1501/125800.

92 Schreiben von Reichskunstwart Redslob an den Reichsminister des Innern, 3.9.1930, BArch, R 1501/125803. 
Die zahlreichen Vorschläge, die immer noch im Reichsministerium des Innern eingingen, folgten allerdings nicht nur diesen drei Haupttendenzen ${ }^{93}$. Redslob hielt fest, dass nach einem ersten Rückgang der Bewerbungen eine neue Welle von Vorschlägen das Ministerium ab 1927 überschwemmte. Denn noch immer war unklar, wie die Entscheidung aussehen würde ${ }^{94}$. Die Situation rief bittere Kommentare hervor, während die Veteranen zunehmend zerstritten waren und sich immer öfter gegen den Bau eines Denkmals und stattdessen für eine bessere Unterstützung der Kriegsopfer aussprachen ${ }^{95}$. Es gab auch offen Spott, wie diese Parabel zeigte:

»Aus einem Geschichtsbuche aus dem Jahre 3000 - Zu jener Zeit hatten die Deutschen einen großen Krieg verloren und beschlossen, für die Gefallenen dieses Krieges ein gemeinsames Ehrenmal zu errichten. Die westlichen Stämme wollten es am Rhein aufstellen wissen, die Ost- und Norddeutschen in der Hauptstadt, die Südländer auf den Alpen und die anderen in Thüringen. Da sich die Deutschen aber niemals einigen konnten, wo das Ehrenmal zu errichten sei, begannen sie untereinander einen großen Krieg darüber, der doppelt so lange dauerte wie jener große erste Krieg, und der Ehrenmalkrieg genannt wird. Als er endlich zu Ende war, beschloss man, für die Gefallenen des Ehrenmalkrieges ein Denkmal zu errichten. Freilich war inzwischen der Rhein von den Franzosen, die Hauptstadt von den Russen, Thüringen von den Tschechen und das Alpenland von den Italienern besetzt; aber zwischen Schilda, Mölla, Krähwinkel und Posemuckel war noch die Wahl für das Ehrenmal der Ehrenmalkrieger frei. Da sich die Überlebenden aber nicht einigen konnten, wo es zu errichten wäre, begannen sie untereinander einen heftigen Krieg um das Ehrenmal, der Ehrenmalnochmalkrieg genannt, dieser dauerte dreimal so lange wie jener große Krieg. Am Schlusse dieses Krieges blieben nur noch vier Deutsche am Leben, die beschlossen, für die Gefallenen der Ehrenmalkriege ein Ehrenmal in ihrer Einsiedelei zu errichten. Da sie sich indessen nicht darüber einig wurden, ob es vor oder hinter, rechts oder links ihrer Blockhütte aufgestellt werden sollte, schlugen sie sich untereinander so lange tot, bis keiner mehr da war. Daher kommt es, dass heutzutage diese einst große Nation ausgestorben ist und nur mehr als Sage existiert ${ }^{96} . "$

Angesichts der wachsenden Zahl immer neuer Pläne schlugen manche vor, ein Denkmal zu nutzen, das erst kurz zuvor errichtet worden war und mit dem Weltkrieg in Verbindung stand: das Tannenberg-Denkmal in Ostpreußen ${ }^{97}$. Aber aufgrund seiner dezentralen Lage und der Ideologie seiner Initiatoren konnte man über die erneute Nutzung dieses Denkmals keine Einigkeit erzielen. Ursprünglich war es zur Erinnerung an den deutschen Sieg in der Schlacht bei Tannenberg erbaut worden, durch den das Vordringen der russischen Truppen 1914 gestoppt

93 Redslob zählte mehr als 300 Vorschläge für das Reichsehrenmal auf: Bericht vom 18.10.1928, BArch, R 1501/125799.

94 Schreiben vom Reichskunstwart Redslob an den Reichsminister des Innern, 12.1.1928, BArch, R 32/353a.

95 Schreiben an den Reichsminister des Innern im Jahre 1928, BArch, R 1501/125799 bis 125804.

96 Abschließendes Motto vom Projekt »Reichsehrenhain und Wartburgstadion « zugunsten eines Reichsehrenmals in der Nähe von Eisenach. Scheiben an den Reichsminister des Innern, Dezember 1927, BArch, R 1501/125801.

97 Vorschläge in diesem Sinne vom Heimatbund Ostpreußen am 10.2.1928, vom Reichsverband der Heimattreuen Ost- und Westpreußens am 19.5.1928, vom Tannenberg-Nationaldenkmalverein am 10.12.1928, BArch, R 1501/125801 f. 
worden war. Das Denkmal sollte aber auch den noch lebenden Hindenburg als den Sieger dieser Schlacht rühmen und die rechtmäßige Zugehörigkeit Ostpreußens zum Deutschen Reich symbolisieren. Dank des Erfolgs der öffentlichen Spendensammlung in nationalistischen und monarchistischen Kreisen konnte am 31. August 1924, zum zehnten Jahrestag des Sieges, der Grundstein für das Ehrenmal gelegt werden. Der Bau erfolgte nach den Plänen der Architekten Walter und Johannes Krüger, die eine achteckige Festung mit keltischen wie auch mittelalterlichen Zügen und einem quadratischen Turm an jeder Seite entworfen hatten ${ }^{98}$. Die Einweihung fand am 18. September 1927 statt, kurz bevor Hindenburg, der während des Krieges zum Generalfeldmarschall ernannt und 1925 zum Reichspräsidenten gewählt geworden war, seinen 80. Geburtstag feierte. 70000 Menschen nahmen daran teil, darunter zahlreiche Mitglieder deutlich rechtsorientierter Vereinigungen. Dagegen waren jüdische und republikanische Organisationen, vor allem das »Reichsbanner Schwarz-Rot-Gold «"9 , von der Feier ausgeschlossen.

Im Frühjahr 1928 wurde die Debatte durch die Gründung eines »Reichsausschusses für das Ehrenmal « noch unübersichtlicher. Dieses Gremium, das sich selbst als national bezeichnete, aber in keiner Weise offiziell war, ernannte sich zum Vertreter der deutschen Volksgemeinschaft als einziger Fürsprecherin der Nation. Der Reichsausschuss wurde von dem Berliner Architekten Bodo Ebhardt geleitet, einer umstrittenen Persönlichkeit, der man nachsagte, Wilhelm II. nahezustehen, und die alle Entscheidungen zugunsten des Projekts eines Ehrenhains bei Bad Berka anfocht, weil hierüber angeblich keine Einigkeit herrschte ${ }^{100}$. Der Reichsausschuss verfügte über wirksame Verbindungen: Im Dezember 1928 veranlasste er den Reichstag dazu, die Regierung erst dann über die Frage des Reichsehrenmals entscheiden zu lassen, wenn der Feind das gesamte Staatsgebiet geräumt habe ${ }^{101}$. In Wirklichkeit ging es darum, jede Entscheidung zugunsten von Bad Berka zu blockieren; der Reichsausschuss sprach sich seinerseits 1929 für einen Standort am Rhein aus. Auf Regierungsebene wurde diese Frage inzwischen nur noch sporadisch angesprochen.

Angesichts dieser Entwicklung befasste sich auch Reichskunstwart Redslob eingehend mit den bestehenden Kräfteverhältnissen. Er kam zu dem Schluss, dass unter den verschiedenen Projekten die Idee des Heiligen Hains den Wünschen der Bevölkerung am besten entspreche, aber die Frage über dessen Standort nach wie vor heikel sei. Berlin brauche als Hauptstadt unbedingt eine Gedenkstätte für die Kriegsgefallenen, aber die Entscheidung, dort das Reichsehrenmal zu errichten, würde in zahlreichen süddeutschen Regionen heftigen Widerstand wecken. Eine Entscheidung für den Rhein hingegen würde den Zorn der östlichen Gebiete hervorrufen, die sich dann vernachlässigt fühlen würden. Daher befürwortete Redslob ein Reichsehrenmal bei Bad Berka, fügte aber hinzu, dass diese Entscheidung

98 Jürgen Tietz, Das Tannenberg Nationaldenkmal. Architektur, Geschichte, Kontext, Berlin 1999; Heike Fischer, Tannenberg-Denkmal und Hindenburgkult. Hintergründe eines Mythos. In: Unglücklich das Land, das Helden nötig hat. Leiden und Sterben in den Kriegsdenkmälern des Ersten und Zweiten Weltkrieges. Hrsg. von Michael Hütt [u.a.], Marburg 1990, S. 28-49.

99 Pressespiegel des Reichslandbundes, BArch, R 8034 II/7691.

100 Schreiben des Reichsausschusses für das Reichsehrenmal an die Reichsregierung, 30.11.1928, BArch, R 1501/125799.

101 Beschluss des Reichstages auf Grund mündlichen Berichts des 19. Ausschusses (Besetzte Gebiete), Sitzung vom 15.12.1928, BArch, R 1501/125799. 
besser akzeptiert werden würde, wenn man nicht nur dieses eine Denkmal errichtete. So könnte die Hauptstadt eine Gedenkstätte für die verlorenen Provinzen und das Rheingebiet einen Ort der Erinnerung an die Besatzung erhalten ${ }^{102}$. Dieser Vorschlag, die Denkmäler »aufzuteilen«, indem mehrere Denkmäler errichtet wurden, kam über das Planungsstadium allerdings nicht hinaus.

In Anbetracht des Zauderns des föderalen Staates machte die - sozialdemokratisch geführte - preußische Staatsregierung geltend, dass Berlin einen Ort brauche, an dem die Besucher die Kriegsgefallenen ehren könnten. Sie beschloss nun zu handeln. Im Juli 1929 ließ der preußische Ministerpräsident Otto Braun (SPD) prüfen, ob die Neue Wache - entworfen von Karl Friedrich Schinkel und errichtet 1816 bis 1818 für die Wache des Königs und als Gedenkstätte für die Gefallenen der Napoleonischen Kriege - ohne großen Kostenaufwand zu einem Ehrenmal für die Kriegsgefallenen umgebaut werden könne (statt zu einem Denkmal für die verlorenen Provinzen, was er als revanchistisch betrachtete). Die Entscheidung für einen solchen Umbau fiel am 26. November $1929^{103}$. Allerdings blieben die hinter dieser Initiative steckenden Gründe im Dunklen. Sollte die Hauptstadt ein preuBisches Denkmal bekommen, das nichts mit den Plänen auf nationaler Ebene zu tun hatte? Oder richtete sich das Vorhaben gegen den Plan des Reichsehrenmals? Innerhalb der Reichsregierung gingen die Meinungen über den Status des geplanten Denkmals und über die Haltung gegenüber der preußischen Regierung auseinander, die das begehrte Gelände, auf dem sich die Neue Wache befand, zu bekommen versuchte.

Der Reichsminister des Innern, Carl Severing, selbst ein Sozialdemokrat, begrüßte die preußische Initiative. Er empfahl eine enge Zusammenarbeit zwischen der Reichs- und der preußischen Regierung, wobei das Deutsche Reich wieder die Oberhand gewinnen sollte. Er schlug vor, aus dem geplanten Denkmal das überfällige Reichsehrenmal zu machen: »Weite Kreise des deutschen Volkes würden es nicht verstehen, wenn in der Reichshauptstadt nicht ein Reichs-, sondern ein preußisches Ehrenmal geschaffen würde [...] Durch eine Beteiligung des Reiches würde weiter die langumstrittene Reichsehrenmalsfrage endlich ihre befriedigende Lösung finden ${ }^{104}$.«In diesem Sinne forderte er, seinem Ministerium, das schon immer für die Frage des Reichsehrenmals zuständig gewesen war, die Verantwortung in dieser Angelegenheit zu übertragen.

Reichswehrminister Wilhelm Groener (parteilos) begrüßte ebenfalls die preußische Initiative. Sein Vorschlag lautete indes, die Zuständigkeit für das künftige Denkmal zu gleichen Teilen der Regierung Preußens als Nachfolgerin des ehemaligen preußischen Kriegsministeriums und der Reichswehr als Nachfolgerin der ehemaligen kaiserlichen Armee zu übertragen ${ }^{105}$. Das geplante Denkmal sollte das Reichsehrenmal nicht ersetzen, aber auch kein rein preußisches Denkmal, sondern ein in erster Linie militärisches Denkmal werden, errichtet durch die verschiedenen Erben der am Krieg beteiligten Armee.

Schreiben von Reichskunstwart Redslob an den Reichsminister des Innern, 18.10.1928, BArch, R 1501/125799.

103 Sitzung des Preußischen Staatsministeriums vom 26.11.1929, BArch, R 1501/125799.

104 Schreiben des Reichsministers des Innern an den Preussischen Ministerpräsidenten, 23.12.1929, BArch, R 1501/125799.

105 Schreiben des Reichswehrministers an den Staatssekretär in der Reichskanzlei, 13.12.1929, BArch, R 1501/125799. 
Reichspräsident von Hindenburg wiederholte seine Überzeugung, dass das Reichsehrenmal seinen Platz den Wünschen der Kriegervereine gemäß in Bad Berka finden sollte. Wenn es ein Denkmal zu Ehren der Gefallenen Preußens oder Berlins geben sollte, so würde er dies befürworten, aber diese zweite Gedenkstätte dürfe nur eine Ergänzung der ersten und kein Ersatz dafür sein ${ }^{106}$.

Tatsächlich gehörte das Gebäude der Neuen Wache der Armee, und die Angelegenheit wurde den preußischen Behörden und dem Reichswehrministerium gemeinsam übergeben. Nachdem erst geplant worden war, das Denkmal als »Gedächtnisstätte für die Gefallenen Preußens und zum Andenken an die Toten des Weltkriegs der alten Armee und Marine « zu bezeichnen, wurde letztendlich der Name »Gedächtnisstätte für die Gefallenen des Weltkrieges « gewählt. Die Reichswehr übernahm die Hälfte der Kosten, machte jedoch klar, dass dieses neue Denkmal trotz seiner allgemeinen Bezeichnung den Plan des Reichsehrenmals nicht behindern sollte ${ }^{107}$

In diesem Punkt bestand allerdings eine ständige Unstimmigkeit zwischen dem Reichswehrministerium und dem Reichsministerium des Innern. Reichswehrminister Groener versuchte, die Tragweite des preußischen Vorhabens zu begrenzen, indem er es unter Kontrolle der Armee hielt, während der Reichsminister des Innern Severing und sein Nachfolger Joseph Wirth im Gegenteil diese Gelegenheit nutzten, um wieder die Initiative zu übernehmen und die Frage des Reichsehrenmals zu klären ${ }^{108}$.

Das Verfahren ging jedoch nach den vom Reichswehrministerium und den preußischen Behörden festgelegten Bedingungen weiter. Es wurde ein Wettbewerb für den Umbau der Neuen Wache ausgeschrieben, und am 15. Juli 1930 wählte die hierzu ernannte Jury unter den sechs konkurrierenden Entwürfen, die eher auf Intimität zielende Arbeit von Heinrich Tessenow aus. Der Berliner Architekt verwandelte das Innere des Gebäudes in einen einzigen großen Saal. In dessen Mitte befand sich ein Altar aus schwarzem Granit mit Kandelabern auf beiden Seiten und einem Eichenkranz aus Edelmetall darauf. Zu seinen Füßen trug eine Bronzeplatte die Inschrift »1914-1918«. Diese Szene wurde durch ein rundes Dachfenster mit Tageslicht beschienen ${ }^{109}$.

Der endgültige Status der Neuen Wache blieb ungeklärt. Der Umbau des Gebäudes geschah in Zusammenarbeit zwischen dem Freistaat Preußen und dem Deutschen Reich, bevor der Reichswehrminister es dem preußischen Finanzminister übergab. Es trug seitdem den recht allgemein gehaltenen Titel »Gedächtnisstätte für die Gefallenen des Weltkrieges«, wobei der Begriff »Gedächtnisstätte« eine deutliche Unterscheidung zu dem auf Reichsebene vorgesehenen »Ehrenmal « ermöglichte. Dieses Projekt machte zwar nur langsame Fortschritte, nahm aber

106 Schreiben des Büros des Reichspräsidenten an den deutschen Reichskriegerbund Kyffhäuserbund, 13.1.1930, BArch, R 1501/125799.

107 Schreiben des Reichswehrministers an den Preussischen Finanzminister, 9.5.1930, BArch, R 1501/125799.

108 Korrespondenz zwischen Severing, Wirth (seinem Nachfolger ab dem 30.3.1930) und Groener, 1930, BArch, R 1501/125799.

109 Niederschrift der Sitzung des Begutachtungsausschusses für den Wettbewerb zur Erlangung von Vorschlägen für eine Gedächtnisstätte für die Gefallenen des Ersten Weltkrieges in der Neuen Wache zu Berlin, 15.7.1930. BArch, R 32/358. Zu den verschiedenen Projekten vgl. Jürgen Tietz, Schinkels Neue Wache Unter den Linden. Baugeschichte 1816-1993. In: Die Neue Wache unter den Linden. Ein deutsches Denkmal im Wandel der Geschichte. Hrsg. von Christoph Stölzl, Berlin 1993, S. 9-93. 


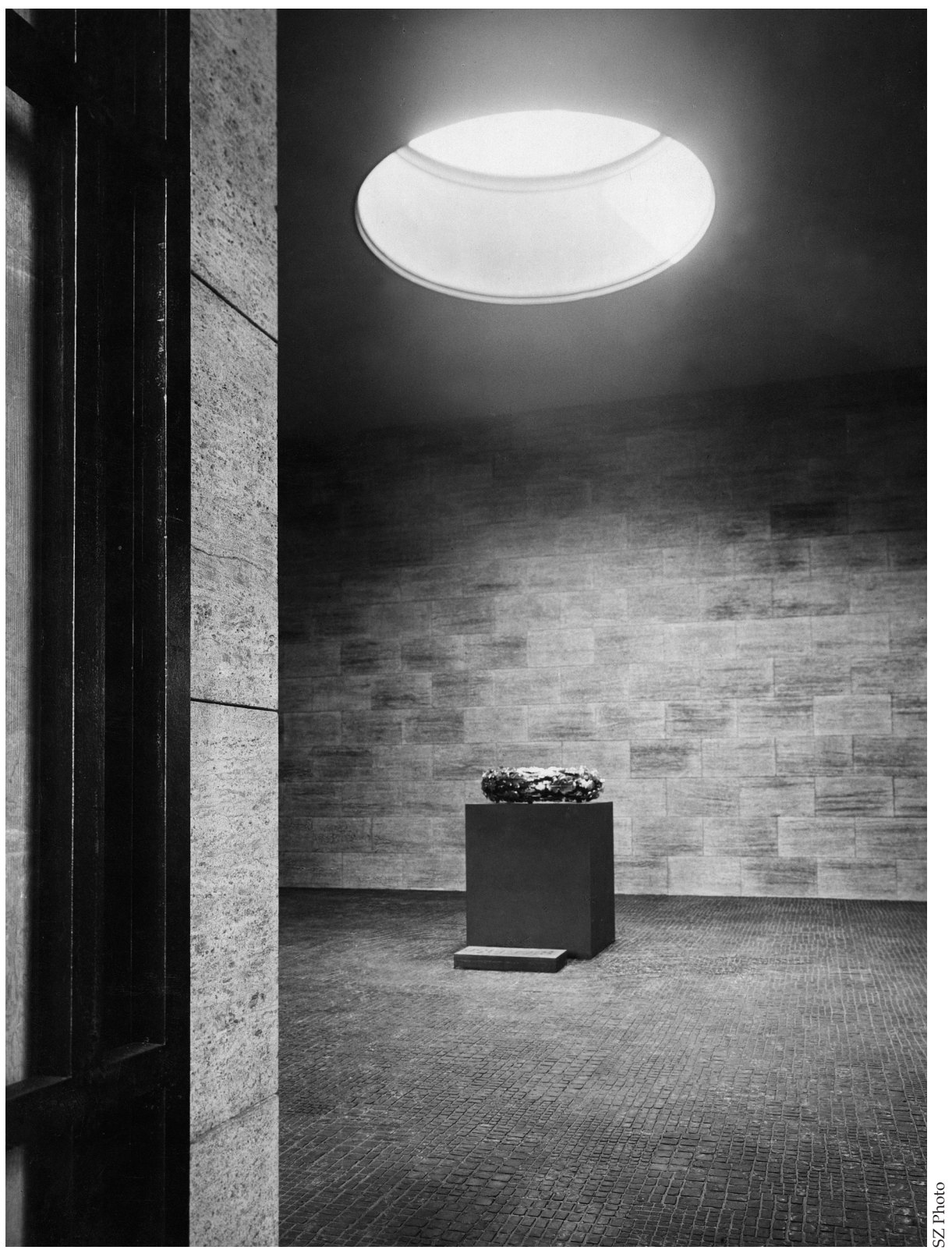

Abb. 2: Neue Wache: Innenraum der Gedächtnisstätte für die Gefallenen des Weltkrieges, 1931. In der Mitte befindet sich auf einem Altar aus schwarzem Granit ein Eichenkranz aus Gold-, Silber- und Platinblättern, der von dem Bildhauer Ludwig Gies gestaltet wurde. 
einen eigenen Verlauf ${ }^{110}$. Am 2. Juni 1931 wurde die Einweihung der Neuen Wache gleichwohl zu einem nationalpolitischen Ereignis. Der preußische Ministerpräsident Otto Braun empfing den Reichspräsidenten und den Reichswehrminister in Anwesenheit von Mitgliedern der deutschen Reichsregierung und der preußischen Regierung, von Armee- und Marineeinheiten sowie Vertretern der Kriegervereine ${ }^{111}$. Braun erklärte, der Ort solle »das Gedächtnis an die Toten des Weltkrieges wachhalten, nicht nur an die Söhne Berlins oder die Preußens, sondern an die gefallenen Söhne des ganzen Deutschland «. Reichswehrminister Groener strich die »heroische Größe« der Gefallenen heraus, deren wieder erwachter Geist die Nation retten werde, und Reichspräsident von Hindenburg ehrte seine treuen Kameraden, deren Andenken zur »inneren Einigkeit « des deutschen Volkes mahnen solle. Alle deutschen Radiosender übertrugen die gesamte Zeremonie $^{112}$.

Die Frage des Reichsehrenmals war allerdings immer noch nicht gelöst. Nachdem die letzten ausländischen Besatzer im Dezember 1929 das deutsche Staatsgebiet geräumt hatten und im März 1930 auf Reichsebene ein Regierungswechsel erfolgt war, sollte das Auswahlverfahren für das endgültige Projekt wieder aufgenommen werden. Die Kriegervereine begannen erneut mit ihrer Kampagne, um eine offizielle Entscheidung für Bad Berka zu erreichen, und erhielten dafür die moralische und finanzielle Unterstützung der thüringischen Landesregierung und des Reichspräsidenten. So beschloss die Reichsregierung am 27. März 1931 zwar spät, aber nicht überraschend, die Einrichtung eines Reichsehrenmals in Form eines Heiligen Hains im Wald bei Bad Berka. Um Unruhen in der Rheinprovinz zu vermeiden, beschloss sie außerdem, ein »Ehrenmal für Einheit und Freiheit« am Rheinufer zu errichten. Auf diese Weise käme es zu einem Gleichgewicht zwischen den verschiedenen Kriegsgedenkstätten: Die Ostgebiete hatten bereits ein Heldenmal in Tannenberg, und die Hauptstadt besaß eine Gedenkstätte mit der Neuen Wache, sodass das Reichsehrenmal seinen Platz logischerweise im Herzen des Landes finden musste. Dass die westlichen Gebiete sich auch mit einem Denkmal für die direkt aus dem Krieg erwachsene Besatzung schmücken konnten, schien nur gerecht ${ }^{113}$.

Im Mai 1931 wurde die Stiftung Reichsehrenmal gegründet. Unter Hindenburgs Ehrenvorsitz versammelte sie Vertreter des Reichs und des Landes Thüringen sowie Vertreter der Krieger- und Kriegsopfervereine. Die Stiftung sammelte sogleich Spenden und schrieb einen Wettbewerb für die Errichtung des Reichsehrenmals aus. Von den eingereichten 1828 Entwürfen prämierte sie zwanzig, die sie im Juni 1932 in Berlin ausstellte ${ }^{114}$. Die Jury entschied sich im Januar 1933 schließlich für den Entwurf von Oswald Bieber und Joseph Wackerle. Die beiden Münchener Professoren schlugen vor, im Herzen des Waldes bei Bad Berka einen Ge-

110 Reichswehrministerium, Die Neue Wache als Gedächtnisstätte für die Gefallenen des Weltkrieges, Berlin 1931, BArch, R 43 I/712.

111 Bei den Einladungen an die Verteranenvereine wurde sehr darauf geachtet, dass sie ein möglichst großes politisches Spektrum abdeckten, um aus dem neuen Gedenkort ein Integrationssymbol der Republik zu machen. Gleichwohl wurde die Einweihungsveranstaltung von vielen boykottiert, von Monarchisten und vom »Stahlhelm«, der am selben Tag ein reichsweites Treffen in Breslau organisierte. Saehrendt, Der Stellungskrieg (wie Anm. 8), S. 133.

112 Berichte zur Einweihung der Neuen Wache, BArch, R 43 I/712.

113 Pressenotiz vom Reichskabinett, 28.3.1931, BArch, R 1501/125799.

114 Zu Einzelheiten des Projekts siehe BArch, R 32/489, R 32/535 und R 43 I/716. 
bäudekomplex zu errichten, der aus einem Denkmal, einem Turm, einem Gedenkraum und einem Wohnhaus bestand.

Hitlers »Machtergreifung " setzte diesem langen Prozess ein Ende. Die neue Führung zeigte keinerlei Interesse am Bau eines Reichsehrenmals in Thüringen; sie bevorzugte eindrucksvollere, weithin sichtbare Bauwerke. Hitler selbst hatte schon in den 1920er Jahren daran gedacht, in Berlin einen Triumphbogen errichten zu lassen. Dieser sollte die gleichen Formen haben wie der Arc de Triomphe in Paris, diesen aber deutlich überragen und die Namen aller deutschen Kriegsgefallenen in Granit verzeichnen. Albert Speer bot im 1939 ein Modell dieses Denkmals an, das am südlichen Ende der Prachtstraße der künftigen Hauptstadt »Germania « stehen sollte ${ }^{115}$. Bis dahin fand das nationalsozialistische Regime sich mit der Neuen Wache ab und begnügte sich damit, dort noch ein Kreuz an der hinteren Wand anzubringen und die vor dem Gebäude Wache stehenden Polizisten durch Soldaten zu ersetzen ${ }^{116}$. Als Hitler am 2. Oktober 1935 außerdem die sterblichen Überreste des im Vorjahr verstorbenen Hindenburg nach Tannenberg überführen ließ, erklärte er das Tannenberg-Denkmal zum »Reichsehrenmal Tannenberg « ${ }^{117}$.

Da es kein allgemeines Kriegsdenkmal gab, setzte sich die Neue Wache in der öffentlichen Meinung rasch als Nationaldenkmal durch. Sie wurde oft sogar als Reichsehrenmal bezeichnet, obwohl sie diesen Status nie besaß, und selbst in den Ministerien herrschte darüber Verwirrung ${ }^{118}$. Ihre zentrale Lage in Berlin stellte sicher einen großen Pluspunkt dar. Schon 1931 erschien sie in den Reiseführern der Hauptstadt ${ }^{119}$, und auch die feierlichen Ehrungen wurden jetzt dort vorgenommen. Am Volkstrauertag im Februar 1932 wurden in der Neuen Wache Kränze des Reichswehrministeriums, des Reichstags, der preußischen Regierung, des »Volksbunds Deutscher Kriegsgräberfürsorge«, zahlreicher Veteranenorganisationen und anderer Verbände niedergelegt - ganz zu schweigen von Tausenden anonym abgelegten Blumen. Diese Szene wiederholte sich in den nächsten Jahren ${ }^{120}$. Die Neue Wache zog zudem das ganze Jahr über neben prominenten Besuchern auch die Berliner selbst an, die manches Mal bedauerten, vor Ort keine Blumen kaufen zu können, um sie vor dem Denkmal niederzulegen ${ }^{121}$. Die Frage, welchen Status das Denkmal besaß, erledigte sich durch seine Nutzung. So stellte die Neue Wache ab 1931 de facto eine nationale Gedenkstätte dar.

115 Albert Speer, Erinnerungen, Frankfurt a.M. 1969.

116 Die Neue Wache als Ehrenmal für die Gefallenen des Weltkriegs, Berlin 1936, S. 8.

117 Tietz, Das Tannenberg Nationaldenkmal (wie Anm. 98); Fischer, Tannenberg-Denkmal (wie Anm. 98). Vor der Ankunft der Roten Armee ließ Hitler das Denkmal im Januar 1945 sprengen.

118 Korrespondenz des Außen- und Innenministeriums, 1932-1933, BArch, R 1501/125799.

119 Korrespondenz des Grieben Verlages an den Reichskunstwart, 9.1.1931, BArch, R 32/358.

120 Pressespiegel des »Stahlhelm«, BArch, R 72/1160.

121 Briefe an den Reichskunstwart, BArch, R 32/358. 


\section{Der Arc de Triomphe und die Neue Wache: Symbolische Umbauten}

Sowohl im Falle des Arc de Triomphe als auch der Neuen Wache wurden bestehende Bauten umgenutzt. Ursprünglich handelte es sich ja um militärische Gebäude, die zu Beginn des 19. Jahrhunderts auf kaiserlichen bzw. königlichen Wunsch in einer Hauptstadt errichtet worden waren. Nach dem Ersten Weltkrieg wurden beide zu Orten persönlichen Gedenkens und gemeinsamer Zeremonien umgewidmet. Neben diesen wesentlichen Ähnlichkeiten der in Paris und Berlin errichteten Nationaldenkmäler sind dennoch Unterschiede feststellbar.

Der erste Unterschied betrifft den zeitlichen Ablauf. Der Kult um den Unbekannten Soldaten am Arc de Triomphe entwickelte sich bei allem Streit bereits am 11. November 1920. Dies war ein früher Zeitpunkt im Vergleich zur Situation in den meisten ehemals kriegführenden Ländern. Die Beisetzung des französischen Unbekannten Soldaten fand am selben Tag statt wie die des britischen, und so wurden die ersten beiden Gedenkstätten dieser Art geschaffen. Die Umwandlung der Neuen Wache in ein Denkmal mit nationalem Anspruch fand dagegen erst dreizehn Jahre nach Kriegsende statt und war nur durch einen institutionellen Umweg möglich. Unter diesen Bedingungen war es schwerer, wenn nicht unwahrscheinlich, dass dieses Denkmal ein Kriegsgedenken tiefgreifend prägte, das sich bereits auf seine eigene Weise entwickelt hatte.

Ein zweiter Unterschied liegt in der Größe der Bauwerke. Der fast 50 Meter hohe Arc de Triomphe an der Place de l'Étoile überragt den gesamten Pariser Westen; er liegt mitten auf einer Kreuzung von zwölf berühmten Straßen und ist damit außerordentlich gut sichtbar. Die Neue Wache ist zwar auch ein glanzvolles Symbol und architektonisches Meisterwerk, hat aber nicht die gleiche Ausstrahlungskraft. Sie liegt vom Brandenburger Tor aus gesehen am unteren Ende und etwas abseits der Prachtstraße Unter den Linden. Sie ist nicht einmal 15 Meter hoch und kleiner als die umstehenden Gebäude: die Universität, das Zeughaus und das Kronprinzenpalais. Dass sie nicht überall bekannt ist, zeigt sich in der Formulierung der Einladung zur Einweihung dieses neuen Denkmals: »Am Dienstag, den 2. Juni 1931 um 12.00 Uhr wird die ehemalige Neue Wache (Schinkelbau) neben dem Zeughause in Berlin nach durchgeführtem Umbau eingeweiht als >Gedächtnisstätte für die Gefallenen des Weltkrieges ${ }^{122}$ « « Die Erwähnung des Gebäudes allein schien nicht auszureichen, um von der breiten Öffentlichkeit erkannt zu werden.

Ein dritter Unterschied zeigt sich in der Art des Gedenkkults. Das Grabmal des Unbekannten Soldaten in Paris ist im Gegensatz zur Erhabenheit des Arc de Triomphe schlicht und nötigt dem Betrachter Respekt ab. Vor allem die physische Anwesenheit des Todes durch den Leichnam des Unbekannten Soldaten verleiht dem Ort einen sakralen Charakter. Wie das Panthéon, der Invalidendom oder Notre-Dame, die ihre Aura ebenfalls der Tatsache verdanken, dass in ihnen Zivilisten, Soldaten oder Geistliche begraben sind, erhielt der Arc de Triomphe durch den unter seinem Bogen ruhenden Soldaten eine neue Bedeutung. 1923 wurde die Anlage durch die Ewige Flamme vervollständigt, die sowohl in der Realität als auch symbolisch für eine dauerhafte Erinnerung sorgen sollte. Zugleich wurde das 
bis heute gültige Ritual eingeführt, sie täglich neu zu entfachen - jeden Tag durch eine andere Veteranendelegation.

Die Neue Wache bot keine so aussagekräftigen Symbole. Weder das Gedenken noch der Tod wurden dort direkt verkörpert. Bei den Überlegungen, wie man dem Gedenkkult in Deutschland eine Form geben könnte, hielten die meisten eine Ewige Flamme dem »Geist der Toten « für angemessen, aber man fragte sich, ob es passend sei, diesen Ritus aus dem Ausland zu übernehmen. Der Gedanke, einen Unbekannten Soldaten beizusetzen, wurde ebenfalls aufgegeben. Stattdessen wurden andere Ideen präsentiert, wie man den Kriegstod auf eindringliche Weise in Erinnerung rufen könnte. So schlug der Maler Ludwig Dettmann vor, von jedem Soldatengrab und von jedem Schlachtfeld Erde zu sammeln und in einem symbolischen Grab zu vereinen. Auf diese Weise könne man die Toten wieder ins Reich zurückholen, sie dort versammeln und alle gemeinsam ehren ${ }^{123}$.

Was das geplante, jedoch nie realisierte Reichsehrenmal betraf, kamen diese Überlegungen zu dem Ergebnis, dass ein Heiliger Hain, der den Tod wieder in den Kreislauf der Natur einbettete, am besten geeignet wäre. Für die Errichtung eines Denkmals in der Stadt stellte der Wettbewerb Anforderungen hinsichtlich der Schlichtheit und Würde. Die verschiedenen Entwürfe nahmen dies auf, indem sie meist christliche Symbole verwandten und mit Licht und Schatten spielten, um eine Art Sakralbau zu schaffen. Selbst der schließlich ausgewählte Entwurf Tessenows erfüllte die Anforderungen nur teilweise. Manche kritisierten ihn als banal und sinnentleert ${ }^{124}$.

Schließlich bot die Neue Wache, ganz wie der Arc de Triomphe, einen geeigneten Hintergrund sowohl für das persönliche Gedenken als auch für gemeinsame Feierlichkeiten. Doch die Neue Wache blieb stets im Hintergrund und schaffte nicht den Aufstieg zu einem mächtigen Symbol, das für sich genommen dem Kriegsgedenken diente.

Die neue Nutzung bereits bestehender Bauten hatte in Paris und Berlin aber auch gleiche Auswirkungen, denn sie führte dazu, dass bereits bestehende Symbole neu interpretiert wurden und neue Gedenkstätten entstanden. Sie änderte damit auch die Landkarte der wichtigsten Symbole in den beiden Hauptstädten.

1920 war der Arc de Triomphe bereits fest in der Pariser Denkmal- und Gedenklandschaft verankert. Napoleon hatte seine Errichtung 1805 beschlossen, um die Siege seiner Armeen zu feiern. Der Bau war 1836 unter der Regentschaft Louis-Philippes fertiggestellt worden, der ihn den Siegen der Revolution und des Kaiserreichs gewidmet hatte. Nach seiner Vollendung entwickelte sich seine Bedeutung entsprechend seiner täglichen und auch außerordentlichen Nutzung, und mit dieser Nutzung veränderte sich die Struktur der Nationaldenkmäler in Paris. 1840 sah die Überführung von Napoleons sterblichen Überresten in den Invalidendom logischerweise als eine unter dem Bogen führende Prozession vor. 1885 wurde der Arc de Triomphe durch die Aufbahrung Victor Hugos an der Place de l'Étoile wieder zum republikanischen Ehrenmal. Aber die anschließende Beisetzung des Dichters im Panthéon diente vor allem dazu, die ehemalige Kirche Sainte-Geneviève wieder zur Ruhmeshalle umzuwidmen und den dort 1791 eingeführten säkularen Kult um wichtige Persönlichkeiten wieder aufleben zu lassen. Die Republik zeigte

123 Projekte von Ludwig Dettmann, BArch, R 32/358 und R 1501/125803.

124 Bewertung der Projekte durch die Kommissionsmitglieder: BArch, R 32/358. Reaktionen der Presse: BArch, R 32/358 b. 
damit mehr Stolz auf diese Männer als auf ihre Soldaten, und das Panthéon nahm durch diese »volksnationale « Dimension den wichtigsten Platz unter den Pariser Denkmälern ein ${ }^{125}$. Aber auch andere Monumente bewahrten sich dort herausragende Positionen: In Notre-Dame fanden die religiösen Feierlichkeiten statt, während der Invalidendom dem Militärkult vorbehalten blieb. Im Osten der Stadt symbolisierte die Bastille das Paris der einfachen Leute und die Place de la République das politische Regime in denjenigen Vierteln, wo es wohl seine treuesten Anhänger fand.

Durch den Ersten Weltkrieg wurde diese Rangordnung teilweise verändert. Der Sieg rief einen Nationalstolz hervor, den die Mitte-Rechts-Regierung durch ihre Nutzung des Arc de Triomphe vor allem bei den Siegesfeiern übertrug. Am 11. November 1920 wurden das Panthéon und der Arc de Triomphe wieder in ein und derselben Zeremonie miteinander verbunden, doch dieses Mal ging der Arc de Triomphe als Sieger daraus hervor, denn er wurde zum nationalen Kriegsdenkmal erhoben. Gleichzeitig wurde er auch mit dem Totengedenken verbunden und erfuhr »eine Art semantischer Verschiebung ${ }^{126}$, denn das Grabmal des Unbekannten Soldaten legte den Sinn des Denkmals fest, das jetzt gleichzeitig ein Symbol des Ruhmes und der Trauer war. Nun löste der Arc de Triomphe das Panthéon nach und nach an der Spitze der Pariser Denkmäler ab. Damit wurden die Champs-Élysées zur Triumphstraße, zu der noch die Place de la Concorde als Anhängsel hinzukam ${ }^{127}$. Der Invalidendom erhöhte sein Ansehen, als 1915 die sterblichen Überreste von Rouget de Lisle, dem Verfasser der »Marseillaise«, hinzukamen, bis zu Beginn der 1930er Jahre gefolgt von jenen der Generäle und Marschälle aus dem Weltkrieg.

Die Landkarte der bestehenden Denkmäler, die sich durch die Stabilität der bereits bestehenden Monumente und das Fehlen größerer neuer Bauten auszeichnete, wurde zwar nicht völlig neu gezeichnet, aber die großen Bauwerke mit Symbolwert lagen nun nach den Kriegsgedenkfeiern mehr im Westen der Stadt. Der »liberal-laizistisch-republikanische« Raum (dessen wichtigste Punkte das Panthéon und die Bastille waren), hatte einem eher »militärischen « Raum (der durch die Place de l'Étoile und den Invalidendom markiert war) Platz gemacht ${ }^{128}$.

In Berlin war die Neue Wache zwischen 1816 und 1818, nach den Befreiungskriegen, nach dem Willen des Preußenkönigs Friedrich Wilhelm III. erbaut worden. Gegenüber der Statue Friedrichs II. und dem Kronprinzenpalais, in unmittelbarer Nähe zum Schloss, war sie ein Symbol der preußischen Monarchie und ihrer Armee, denn sie diente bis 1918 als Wachhaus für die königliche Wache. Das Gebäude, das seitdem über zehn Jahre lang keinem besonderen Zweck gedient hatte, erhielt Anfang der 1930er Jahre eine neue Verwendung. In einer völligen Umkehrung ehrte dieses einst kaiserliche Bauwerk, das damals die Armee beherbergt

125 Avner Ben-Amos, Les funérailles de Victor Hugo. Apothéose de l'événement spectacle. In: Les lieux de mémoire (wie Anm. 4), S. 425-464; Avner Ben-Amos, Monuments and Memory in French Nationalism. In: History and Memory, 5 (1993), 2, S. 50-81.

126 Prost, Les anciens combattants (wie Anm. 60), S. 36.

127 Auch wenn die Place de la Concorde seitdem nicht mehr die mobilisierende Wirkung entfaltet wie die Statue von Strasbourg, die von 1871 bis 1918 in Schwarz gehüllt war. Tartakowsky, La construction sociale (wie Anm. 18).

128 Im Vergleich mit dem »national-militärisch-imperialen « Dreieck des Pariser Westens (Place Vendôme, Étoile, Invalides), das ein Erbe der ersten Hälfte des 19. Jahrhunderts ist, hat die Place Vendôme ihre Bedeutung verloren, während die Place de la Concorde an Bedeutung gewonnen hat. Maurice Agulhon, Paris. La traversée d'est en ouest. In: Les lieux de mémoire (wie Anm. 4), S. 4589-4622. 
hatte, nun nach dem Beschluss der Republik ihre Toten. Aber die Landkarte der Berliner Denkmäler erfuhr dadurch keine einschneidende Änderung.

Dies lag vor allem daran, dass im Deutschland des 19. Jahrhunderts die Regierungen und die mit ihnen verbundenen Denkmäler, die in Folge gebaut oder umgewidmet wurden, nicht so schnell gewechselt hatten. Die preußischen Herrscher hatten ihre Macht mit großer Kontinuität in der Prachtstraße Unter den Linden zur Schau gestellt, sodass diese ab 1815 zu einer regelrechten Triumphstraße wurde ${ }^{129}$. Der liberale bürgerliche Einfluss auf diese Darstellung des Staates beschränkte sich auf einige wenige Statuen, mit denen einzelne Persönlichkeiten der vorwilhelminischen Epoche geehrt wurden, während die seltenen oppositionellen Gedenkstätten der republikanischen oder Arbeiterbewegung sich außerhalb des historischen Stadtkerns in den Arbeitervierteln im Berliner Osten befanden ${ }^{130}$.

Die Weimarer Republik erbte auf diese Weise für ihre Selbstdarstellung Gebäude und Symbole des Kaiserreichs zu eben dem Zeitpunkt, als diese durch die Niederlage und die Revolution ihren Sinn verloren. In den 1920er Jahren blieb diese Machtarchitektur bestehen, aber der Schwerpunkt ihrer Symbole verschob sich langsam vom unteren an das obere Ende der Straße Unter den Linden. Der gewachsenen Bedeutung des Reichstagsgebäudes hatten das leere Schloss und die aufgegebene Neue Wache nichts entgegenzusetzen. Als Zeichen eines politischsymbolischen Ausgleichs wurde der große Platz vor dem Reichstag 1926 von »Königsplatz« in »Platz der Republik« umbenannt. Weil jedoch ständig die Gefahr neuer Kontroversen bestand, hatte die Regierung auch bei den Symbolen Schwierigkeiten, sich zu behaupten.

Durch den Umbau der Neuen Wache kam dem unteren Ende der Straße Unter den Linden in den Erinnerungsfeiern zu Beginn der 1930er Jahre wieder etwas mehr Ehre zu. Das bedeutete jedoch keinen Bruch, weil der daneben liegende Lustgarten immer wieder für republikanische Versammlungen genutzt worden war. Es kam sogar vor, dass das daneben liegende Zeughaus für feierliche Ehrungen genutzt wurde. Mit der Einweihung der Gedächtnisstätte für die Gefallenen des Weltkrieges 1931 wurde das Viertel außerdem in gewisser Weise wieder von den Republikanern übernommen. Aber diese »Republikanisierung « war umkehrbar. Hitler hatte keinerlei Schwierigkeiten, die Neue Wache für sich und sein Umfeld wieder für antidemokratische Zwecke zu verwenden ${ }^{131}$.

\section{Die Hauptstädte und die übrigen Landesteile}

Als Hauptstädte konnten Paris und Berlin aufgrund der Rolle, die sie im nationalen Gefallenengedenken spielten, ihre Position in der Konfrontation mit den übrigen Landesteilen verbessern. In Frankreich überraschte es nicht, dass sich Paris

129 Via triumphalis. Geschichtslandschaft »Unter den Linden« zwischen Friedrich-Denkmal und Schlossbrücke. Hrsg. von Helmut Engel und Wolfgang Ribbe, Berlin 1997.

130 Jürgen Kocka, Öffentlichkeit und Repräsentation in der Reichshauptstadt Berlin. In: Von der Bonner zur Berliner Republik. Öffentlichkeit und öffentlicher Raum in Berlin. Hrsg. von Gina Angress, Berlin 1998, S. 31-51.

131 Wolfgang Kruse, Schinkels Neue Wache in Berlin. Zur Geschichte des modernen politischen Kults in Deutschland. In: Zeitschrift für Geschichtswissenschaft, 5 (2002), S. 419-435. 
als Zentrum des Gedenkens für das ganze Land durchsetzte. Es war logisch, dass das Nationaldenkmal für den Krieg dieser Stadt zukam, in der die Identifizierung mit der Nation fest verwurzelt war. In diesem Punkt hatten die Abgeordneten der Nationalversammlung die Frage mit dem Gesetz vom 25. Oktober 1919 schon früh entschieden. In einigen Punkten wurde dieses Gesetz zwar nicht eingehalten, aber die Wahl von Paris als Standort für das Kriegsgedenken wurde durchgesetzt. In Paris war die Einzigartigkeit des Denkmals garantiert, und damit konnte es auch im übrigen Land keine Konkurrenz bekommen. Andersherum verlieh die auf diese Weise in der Hauptstadt neu errichtete Gedenkstätte der Stadt eine zusätzliche Aura und bestätigte Paris in seiner nationalen Überlegenheit.

Natürlich wurden auch im übrigen Land zahlreiche Denkmäler unterschiedlicher Größe erbaut: Ehrenmäler für die Gefallenen der verschiedenen Orte, Denkmäler zu Ehren besonderer Gruppen, Kampfeinheiten oder sogar eines militärischen Führers, und manchmal auch Denkmäler zur Erinnerung an ein bestimmtes Ereignis, meistens eine Schlacht. Der Staat trug zwar nicht immer zu ihrer Errichtung bei, aber er behielt immer die Kontrolle über die Genehmigung ihres Baus ${ }^{132}$. Damit stellte er sich einigen Initiativen entgegen, die der Vormachtstellung des Grabmals des Unbekannten Soldaten in Paris hätten schaden können. Als zum Beispiel die ehemaligen Soldaten der französischen Orientarmee (Armeé française $\mathrm{d}^{\prime}$ Orient) die sterblichen Überreste eines im Orient gefallenen nicht identifizierten Soldaten nach Marseille überführen wollten, waren die Abgeordneten dagegen, weil dies ihrer Meinung nach »die durch den französischen Unbekannten Soldaten dargestellte symbolische Einheit [zerstören und] deren große und schöne Bedeutung « ${ }^{133}$ schwächen würde. Stattdessen wurde in Marseille ein Denkmal zu Ehren der Orientarmee errichtet, das mit umfangreichen öffentlichen Mitteln unterstützt wurde. Und schließlich brauchten private Initiativen, wenn sie sich hohe Ziele steckten, viel Zeit bis zur Realisierung ihrer Vorhaben. So wurde das nationalistisch angehauchte Denkmal für den Waffenstillstand von Compiègne erst 1927 eingeweiht, und das Beinhaus von Douaumont, das an ein Grabmal erinnerte, war zwar ab 1927 zugänglich, wurde aber erst 1932 fertiggestellt und eingeweiht. Aber nichts davon war hinsichtlich des Gedenkens in den 1920er Jahren eine echte Konkurrenz für den Arc de Triomphe in Paris.

Für Berlin lässt sich nicht so eindeutig sagen, ob die Hauptstadt durch die Kriegsgedenkstätte als Ort nationalen Gedenkens gestärkt wurde. Die Frage stellte sich erst zu dem Zeitpunkt, als der Gedanke der Errichtung eines Nationaldenkmals 1924 offiziell aufgebracht wurde. Dieses Denkmal fand bezeichnenderweise nicht so selbstverständlich seinen Platz in der Hauptstadt, zumindest nicht in den Augen aller und auch nicht ohne Diskussion. Genauso bezeichnend war es, dass sich außerhalb Berlins kein klarer Standort herauskristallisierte. Die Hauptstadt konkurrierte nicht unmittelbar mit anderen Standorten, aber sie setzte sich auch nicht spontan im ganzen Land als wichtigster Ort der Verkörperung des nationalen Gedenkens durch, das zudem ein Problem blieb.

Dies lag zuerst einmal daran, dass die aus dem 19. Jahrhundert stammende Bezeichnung »Nationaldenkmal« den Gedanken aufkommen ließ, der Bau eines Krie-

133 Projet de loi portant ouverture d'un crédit de 200000 francs en vue d'une subvention pour l'érection d'un monument en l'honneur de l'armée d'Orient. Chambre, 24.11.1921, JO Chambre/DP, S. 223. 
gerdenkmals schließe unmittelbar an die früheren Bauten an und ergänze eine größtenteils bereits im Kaiserreich begonnene Errichtung von Denkmälern überall im Staatsgebiet ${ }^{134}$. Aber ein derartiges Projekt hob die erlittenen Opfer nicht deutlich genug heraus: Das Denkmal an den Weltkrieg sollte etwas anderes sein, und aus diesem Grund setzte sich bald die Bezeichnung »Reichsehrenmal « durch ${ }^{135}$. Mit diesem Denkmal sollte die Einheit der Nation durch das Totengedenken hergestellt werden. In dieser Hinsicht kann man den Plan für Bad Berka als einen Versuch verstehen, verschiedene Kriegsinterpretationen miteinander zu vereinen. Bemerkenswerterweise verzichtete keiner der an diesem Projekt beteiligten Kriegervereine zugunsten radikalerer Initiativen auf seine Fertigstellung. Jeder vertrat im Namen der Einheit der ehemaligen Krieger weiterhin, was allen zusammen als der einzig mögliche Kompromiss erschien. Dieses Streben nach einem gemeinsamen Sinn und einer nationalen Einheit scheiterte schließlich, als es sein Ziel schon fast erreicht zu haben schien.

Während in Frankreich die wichtigsten Denkmäler in der Hauptstadt standen, entwickelte sich daher in Deutschland langsam ein landesweites Netz von Denkmälern, was zu einem gewissen gesamten Gleichgewicht führte. Allerdings war die Verteilung der Denkmäler innerhalb des Staatsgebiets sowohl auf die offen zur Schau gestellte geografische Komplementarität als auch auf tiefe politische Rivalitäten zurückzuführen. Für einen Teil der Bevölkerung war das in Thüringen geplante Denkmal in seiner Interpretation des Krieges zu vage, um sie wirklich zufriedenzustellen. Die nationalistische Rechte errichtete ihr Denkmal in Tannenberg, auf einem der wenigen Schlachtfelder auf deutschem Boden. Die republikanische Linke reagierte darauf mit dem Umbau der Neuen Wache in Berlin, das gleichzeitig Zentrum der Republik und fortschrittliche Metropole war. Trotz der Bemühungen der preußischen Regierung um eine allgemeine Anerkennung dieses Denkmals, wurde dessen Einweihung von monarchistischen Kreisen boykottiert, die Neue Wache blieb also sogar auf nationaler Ebene republikanisch inspiriert.

Dennoch war klar, dass die Neue Wache deshalb für die Umsetzung eines Denkmals mit nationaler Bedeutung ausgewählt wurde und sich in dieser Rolle durchsetzen konnte, weil sie in der Hauptstadt lag. Genauer gesagt war zweifellos die Tatsache, dass die Neue Wache in der Hauptstadt Preußens befand, dafür verantwortlich, dass sie für die Umsetzung eines preußischen Denkmals ausgewählt wurde, und da die Hauptstadt Preußens gleichzeitig die Hauptstadt des Deutschen Reiches war, konnte das Denkmal eine noch größere Rolle spielen, als ihm ursprünglich zugedacht worden war. Hier füllte es eine tatsächlich bestehende Lücke für die oft in Berlin stattfindenden Gedenkfeiern. So konnte der Standort dieses Denkmals die Stellung der Hauptstadt in den Augen der Berliner, der Deutschen und des Rests der Welt nur stärken.

134 Thomas Nipperdey, Nationalidee und Nationaldenkmal in Deutschland im 19. Jahrhundert. In: Historische Zeitschrift, 206 (1968), 3, S. 529-585; Alings, Monument und Nation (wie Anm. 90).

135 Redslob, Denkschrift zu der Frage des Reichsehrenmals, 15.2.1926, BArch, R 32/353. 


\section{Fazit: Auf dem Weg zu einer »in Stein gemeißelten« Nationalisierung}

In Frankreich wie auch in Deutschland wurden sowohl das Gedenken als auch die Hauptstädte »nationalisiert«. Durch ihren Standort in den Hauptstädten erhielten die Denkmäler den Status von Nationaldenkmälern und trugen damit zu einer Art der nationalen Vereinnahmung des Gedenkens in Form von Denkmälern in den beiden Ländern bei. Dass solche Denkmäler in den Hauptstädten standen, stärkte wiederum deren Stellung innerhalb des jeweiligen Landes. Alles was dort, vor allem im Umfeld dieser Denkmäler, geschah, fand ein besonderes Echo und bekam leicht einen nationalen Anstrich.

Dennoch war die Lage in beiden Ländern verschieden. Auf französischer Seite wurde nach dem Sieg schnell eine Entscheidung getroffen, und in der Hauptstadt entwickelte sich eine starke nationale Symbolik. Auf deutscher Seite fiel die erste Entscheidung erst spät im Rahmen eines problematischen Gedenkens, und die Umsetzung zog sich hin, wobei bereits die Einigung in der Standortfrage schwer fiel. Schließlich entstand eine nationale Symbolik in der Hauptstadt, die eine Hauptstadt im zweifachen Sinne wurde: Berlin blieb in erster Linie preußische Hauptstadt, während es sich gleichzeitig allmählich als deutsche Hauptstadt durchsetzte.

Diese Unterschiede tragen dazu bei, in der jeweiligen Nation verwurzelte Identitäten besser zu verstehen. In Frankreich konnte die Figur des Unbekannten Soldaten die individuellen, politischen und sozialen Widersprüche mehr oder weniger überwinden und zu einem nationalen Symbol werden, das zwar offen blieb, aber als Sinngeber für die Akteure und die Opfer des Krieges fungierte. In Deutschland lässt sich das lange Fehlen eines solchen Symbols zum einen durch das föderale System erklären, in dem es kein vergleichbares Zentrum gab, zum anderen und mehr noch durch »das nie völlig homogenisierte Nationalbewusstsein der Deutschen ${ }^{136}$. Ob es nun um den Plan für ein Denkmal im Wald oder am Rhein ging: Die Überlegungen betrafen weniger das Kriegsgedenken als vielmehr das Symbol, das den deutschen Charakter am besten widerspiegeln würde. Die Natur sollte über die aufeinanderfolgenden Jahreszeiten oder den ständigen Fluss den Kreislauf des Heldentodes und der nationalen Wiederauferstehung wirksamer symbolisieren als das Kunstwerk eines Denkmals. Die einvernehmliche Entscheidung für eines dieser Modell blieb allerdings aus, sodass letztlich ein anderer Entwurf in Berlin realisiert wurde.

Schließlich stellte sich heraus, dass Staaten ein anerkanntes nationales Ehrenmal für ihre Gefallenen nur in ihren Hauptstädten errichten konnten. Im Falle Frankreichs wurde Paris zur symbolischen Hauptstadt des Kriegsgedenkens, weil der Staat nur diese Stadt als Standort für das Ehrenmal des Unbekannten Soldaten bestimmen konnte ${ }^{137}$. In Deutschland stand der Staat kurz davor, ein Nationaldenkmal an einem anderen Ort als Berlin zu errichten. Aber auf die Initiative der

136 Reinhart Koselleck, Erinnerungsschleusen und Erfahrungsschichten. Der Einfluss der beiden Weltkriege auf das soziale Bewusstsein. In: Reinhart Koselleck, Zeitschichten, Studien zur Historik, Franfurt a.M. 2000, S. 278.

137 Jean-Louis Robert, Les monuments aux morts de la Grande Guerre à Paris. In: Capitales culturelles, capitales symboliques. Paris et les expériences européennes, XVIII ${ }^{\mathrm{e}}-\mathrm{XIX} \mathrm{P}^{\mathrm{s}}$ siècles. Ed. par Christophe Charle et Daniel Roche, Paris 2002, S. 149-158. 
preußischen Staatsregierung hin, der sich die Reichsregierung schnell anschloss, entstand das, was bald als zentrales Ehrenmal für die Kriegsgefallenen galt, schließlich doch in der preußischen und deutschen Hauptstadt. In beiden Fällen war die verschieden starke Vereinnahmung der Hauptstädte durch den Staat weniger das Werk der lokalen Akteure als vielmehr nationaler Akteure, die von außen auf sie einwirkten.

\begin{abstract}
At the end of the First World War, the memories of the conflict which developed in France and Germany diverged widely. However, Paris and Berlin were something else than just a genuine reflection of their respective national context; their status as capital cities gave them common characteristics. Therefore some similar phenomena appear. On the one hand, those cities may offer a national backing to particular memories, which was especially sought. On the other hand, the concentration of marks of memory in those cities tended to consolidate them in an always more exclusively national role. Thus, a kind of reciprocal nationalization of memory by capital cities and of capital cities by memory occurred. This nationalization is particularly visible in the analysis of the national monuments that emerged in the post-war years. Nevertheless, such phenomena underline variations between Paris and Berlin: Paris stood out without any difficulty as the capital of France, even of the Allied world, while Berlin stood out as the capital of Prussia, with more difficulty as the capital of Germany.
\end{abstract}

